\title{
Fireside Corrosion of Heat Exchanger Materials for Advanced Solid Fuel Fired Power Plants
}

\author{
Stefano Mori ${ }^{1}$ (D) $\cdot$ Andy Pidcock ${ }^{1} \cdot$ Joy Sumner ${ }^{1} \cdot$ Nigel Simms $^{1} \cdot$ John Oakey $^{1}$
}

Received: 14 June 2020 / Revised: 11 April 2021 / Accepted: 2 December 2021 /

Published online: 18 December 2021

(c) The Author(s) 2021

\begin{abstract}
To address the challenge of climate change, future energy systems need to have reduced greenhouse gas emissions and increased efficiencies. For solid fuel fired combustion plants, one route towards achieving this is to increase the system's steam temperatures and pressures. Another route is to co-fire renewable fuels (such as biomass) with coals. Fireside corrosion performance of two candidate superheater/ reheater alloys has been characterised at higher heat exchanger surface temperature. Samples of the alloys (a stainless steel, Sanicro 25 and a nickel-based alloy, IN740) were exposed in fireside corrosion tests at $650{ }^{\circ} \mathrm{C}, 700{ }^{\circ} \mathrm{C}$ and $750{ }^{\circ} \mathrm{C}$, in controlled atmosphere furnaces using the 'deposit recoat' test method to simulate superheater/ reheater exposure for $1000 \mathrm{~h}$. After exposure, the samples were analysed using dimensional metrology to determine the extent and distributions of corrosion damage in terms of surface recession and internal damage. At $650{ }^{\circ} \mathrm{C}$, the stainless steel and nickel-based alloy performed similarly, while at $700{ }^{\circ} \mathrm{C}$ and above, the median damage to the steel was at least 3 times greater than for the nickel-based alloy. Optical and electronic microscopy studies were used to study samples' damage morphologies after exposure. Intergranular damage and pits were found in sample cross sections, while chromium depletion was found in areas with internal damage. For high-temperature applications, the higher cost of the nickel-based alloy could be offset by the longer life they would allow in plant with higher operating temperatures.
\end{abstract}

Keywords Fireside corrosion $\cdot$ Nickel-based alloy $\cdot$ Stainless steel $\cdot$ Dimensional metrology $\cdot$ Internal damage $\cdot$ Surface recession

Stefano Mori

stefano.mori@cranfield.ac.uk

1 Cranfield University, College Road, Cranfield, Bedfordshire MK43 0AL, UK 


\section{Introduction}

To address the challenge of climate change, future energy systems need to have reduced greenhouse gas emissions [1-6]. For combustion plant using solid fuels, one route towards achieving this is to increase steam system temperatures and pressures, and therefore improve plant efficiency to reduce greenhouse gas emissions per unit energy. Another route is to co-fire renewable fuels (such as biomass) with coals to reduce the net $\mathrm{CO}_{2}$ emissions and so the overall carbon impact of power generation [7-10]. Both of these routes cause issues related to the degradation of the heat exchanger materials. A move to 'advanced ultra-supercritical' (AUSC) or 'hyper-supercritical' (HSC) conditions-steam temperatures above $650{ }^{\circ} \mathrm{C}$ and pressures up to 350 bar-places greater importance on the mechanical properties of heat exchanger tubes, which requires the use of expensive, high nickel stainless steels or even more costly nickel-based alloys for the higher temperature parts [11]. Several studies have looked at these alloy types in such conditions [6, 12-19]; however, the main focus has been on the mechanical behaviour and associated life prediction; they do not provide an understanding of the fireside corrosion performance of the materials.

However, fireside corrosion performance is of great importance when selecting alloys for use in these heat exchangers, due to the complex dependence of such degradation on the exposure conditions (such as metal temperature). The move to higher steam temperatures going to AUSC (or HSC) operations means an accompanying increase in heat exchanger metal temperatures. Due to the characteristic bell-shaped curve associated with the fireside corrosion damage of stainless steels in coal dominated fired systems solid fuel [20], this implies that the distribution of corrosion damage around the heat exchanger network will change with the increase in local metal temperature: some regions may have metal temperatures that are hotter than the damage peak temperature, leading to relatively lower damage rates as temperature rises, while other regions with cooler metal temperatures (that are closer to those associated with damage peak) result in higher damage rates [21]. Co-firing of biomass with coal will additionally cause changes in the composition of the combustion gas stream and any resulting deposits, forming potentially more corrosive surface environments. Such changes can alter the bell-shaped distribution of damage on the fireside heat exchanger's surfaces as different species are active [16, 22-24]. As such, plants firing large fractions of biomass may be limited to run at lower temperatures than conventional coal fired plant, to prevent rapid failure [25].

This work focuses on characterising the behavior of two candidate superheater/ reheater alloys in laboratory simulated co-combustion environments at $650{ }^{\circ} \mathrm{C}$, $700{ }^{\circ} \mathrm{C}$ and $750{ }^{\circ} \mathrm{C}$, spanning the higher temperature end needed for AUSC heat exchangers in the future. The materials investigated in this work are a high chromium austenitic stainless steel and a nickel-based alloy, which were developed to work in coal combustion plants above $650{ }^{\circ} \mathrm{C}$. Sanicro 25 would represent a cheaper alternative than IN740 (the Cr content (around 22.5\%) provide this alloy with a good oxidation resistance [26]), even though IN740 has been reported to have a good corrosion resistance at temperatures above $700{ }^{\circ} \mathrm{C}$ [27]. Sanicro 25 has been 
Table 1 Materials used with trade name and measured chemical composition (weight percentage)

\begin{tabular}{lrlllllllllllll}
\hline Trade name & $\mathrm{Fe}$ & $\mathrm{Ni}$ & $\mathrm{Cr}$ & $\mathrm{Co}$ & $\mathrm{Mo}$ & $\mathrm{C}$ & $\mathrm{Si}$ & $\mathrm{Mn}$ & $\mathrm{Al}$ & $\mathrm{Ti}$ & $\mathrm{Nb}$ & $\mathrm{Cu}$ & $\mathrm{N}$ & $\mathrm{W}$ \\
\hline Sanicro 25 & 42.0 & 24.7 & 22.9 & 1.7 & & $<0.1$ & 1.1 & 0.4 & & & 0.3 & 2.5 & 0.6 & 3.8 \\
Alloy 740 & 0.2 & 49.0 & 25.0 & 20.1 & 0.4 & $<0.1$ & 0.4 & 0.4 & 1.2 & 1.5 & 1.8 & & & \\
\hline
\end{tabular}

Fig. 1 Example of a tube segments used for corrosion exposures

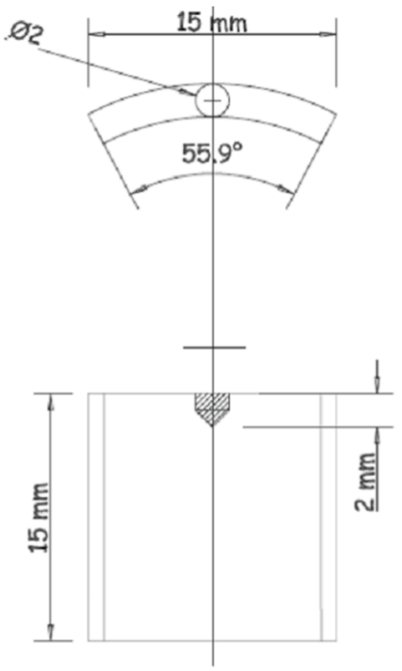

reported, also, to form a chromia scale under fireside exposure at $650{ }^{\circ} \mathrm{C}$, as well as a $\mathrm{Cr}$ depleted zone underneath the oxide scale [26]. The temperatures used in this work are those anticipated for heat exchanger in future AUSC power plants for which there is a need for better understanding of the potential degradation rates and routes to enable better informated materials selection. Furthermore, there is a need to understand the behaviour of such materials in a co-fired fireside corrosion environment at such higher steam temperatures.

\section{Materials and Methods}

\section{Heat Exchanger Materials}

Two materials were selected for use in this study based on their potential for use in superheater/reheaters under potential new, challenging AUSC conditions: one austenitic stainless steel (Sanicro 25) and one nickel-based alloy (IN740). The nominal alloy compositions are given in Table 1. These alloys were available in long super heater tubes which were machined into segment specimens (Fig. 1). Typical specimens' dimensions were $\sim 15 \mathrm{~mm}$ long $\times \sim 15 \mathrm{~mm}$ wide with a $\sim 4 \mathrm{~mm}$ wall thickness. All the specimens surfaces were given a UK 600 grit finish. 


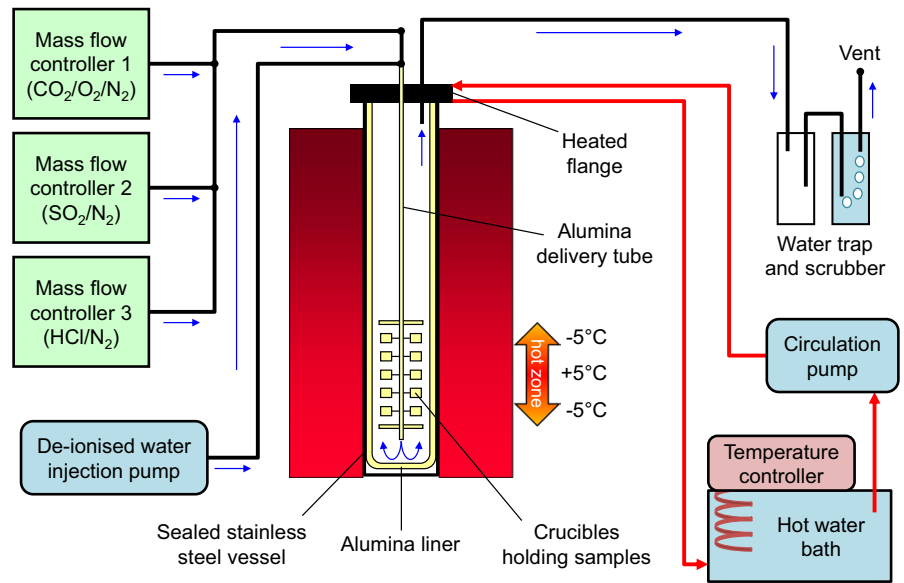

Fig. 2 Schematic diagram of the controlled atmosphere furnaces used for high temperature exposure [23, $25,28]$

Table 2 Gas composition used to simulate co-combustion environment

\begin{tabular}{llllll}
\hline $\mathrm{N}_{2}$ & $\mathrm{O}_{2}$ & $\mathrm{CO}_{2}$ & $\mathrm{SO}_{2}$ & $\mathrm{HCl}$ & $\mathrm{H}_{2} \mathrm{O}$ \\
\hline Balance & $4.0 \%$ vol & $13.6 \%$ vol & $1400 \mathrm{vpm}$ & $400 \mathrm{vpm}$ & $7.1 \% \mathrm{vol}$ \\
\hline
\end{tabular}

\section{Environment Simulation}

Fireside corrosion tests were carried out in an alumina-lined, controlled-atmosphere, vertical tube furnaces (Fig. 2). These furnaces could accommodate 24 samples at a time, in individual alumina crucibles. Each test was run for $1000 \mathrm{~h}$, in $200 \mathrm{~h}$ cycles, using the well-established 'deposit recoat' technique [22, 23].

Prior to their exposure, samples were cleaned using acetone then iso-propanol (IPA) in an ultrasonic bath for 10 min each. Dimensional metrology was performed on the clean samples using a digital micrometer (resolution of $1 \mu \mathrm{m}$ ). The cleaned and measured samples were then brush painted with deposit slurries to give coverage of $\sim 20 \mathrm{mg} / \mathrm{cm}^{2}$ of dried deposit (deposit composition $37.5 \mathrm{~mol} \% \mathrm{Na}_{2} \mathrm{SO}_{4} / 37.5 \%$ $\mathrm{K}_{2} \mathrm{SO}_{4} / 25 \% \mathrm{Fe}_{2} \mathrm{O}_{3}$, widely used in fireside corrosion screening tests [21, 23]) to simulate accelerated corrosion damage [21, 23, 28, 29]. The deposits components were dispersed in iso-propanol. Pre-mixed gases were supplied to the furnace via mass flow controllers, at a flow rate of $100 \mathrm{~cm}^{3} / \mathrm{min}$, to achieve the desired gas composition (Table 2, similar to [23, 28, 30]). Moisture levels were obtained by injecting water into the furnace using a peristaltic pump. Backflow was prevented by connecting the furnace to a vented exhaust line, and the gas inlet has been placed at the opposite end of the furnace to the outlet. The gas mixture was modelled to achieve an environment similar to the one of co-combustion of coal and cereal co-products (CCP) $(20 \%)$.

When the test was cycled, every $200 \mathrm{~h}$, samples were taken from the furnace, and deposits were reapplied on each sample $\left(\sim 20 \mathrm{mg} / \mathrm{cm}^{2}\right)$ after cooling down. As 
part of this deposit recoat process, the samples and crucibles were weighed before and after each cycle. Weight change data were not used to evaluate the progress of corrosion damage, but to identify individual samples and control the deposition fluxes. Individual samples were exposed for 200, 400, 600, $800 \mathrm{~h}$ at each temperature, while 3 samples of each alloy were exposed for $1000 \mathrm{~h}$ at each temperature, to determine the repeatability of the results (a total of 7 deposit-coated samples per alloy were exposed at each test temperature). In addition to exposing samples coated with deposit, bare samples (i.e., without a deposit) were also exposed to provide a baseline reference that is needed for analysis of the dimensional metrology data (as described in the following section).

\section{Analytical Techniques}

After exposure, cross sections through each sample were prepared for analysis. To avoid the loss of deposit/scale from the sample, a cold mounting process was performed (utilising glass ballotini beads mixed with low shrinkage epoxy resin) followed by cutting, grinding, and polishing using non-aqueous lubricants.

Dimensional metrology was used to generate statistical distributions of corrosion damage data for each exposed sample [31-34]. Pre-exposure metrology data were collected before exposure. In this methodology after exposure, polished sample cross sections were measured using an image analyser to record the locations of any remaining metal and internal damage. The $x-y$ coordinates of the metal surfaces and internal damage were obtained from the image analyser. The coordinates were then compared with the damage of the sample without deposit, exposed to the same environment to isolate the damage specifically caused by the deposit; this is a necessary step as the corrosive deposit was only applied to one face of the samples. The data showing the extent of metal change at the sample surfaces were then plotted and ordered to produce cumulative probability curves showing damage distributions associated with each material/deposit/gas/temperature combination. A schematic diagram of the process is given in Fig. 3. Unexposed reference samples were also measured for each alloy to check the differences between pre- and post-exposure metrology processes.

The fireside corrosion damage is either presented as 'metal change' (a negative number showing the amount of material lost) or 'sound metal change' (metal change and any visible internal damage) as a function of cumulative probability. The "metal change" data give an indication of how much the metal interface has regressed with respect to the original (i.e. pre-exposure) surface; this is different from scale/deposit thickness measurements. These datasets were the key output of this study and were produced in line with current standards for high-temperature corrosion assessment $[31,33]$. Use of these statistical methods for analysing corrosion data is becoming more widespread and provides a good basis for corrosion model development and validation $[20,35]$.

The polished cross sections were also examined by scanning electron microscopy (SEM) to investigate the scale layers microstructure that had formed on the materials. Energy-dispersive X-ray spectroscopy (EDX) was used to identify the 

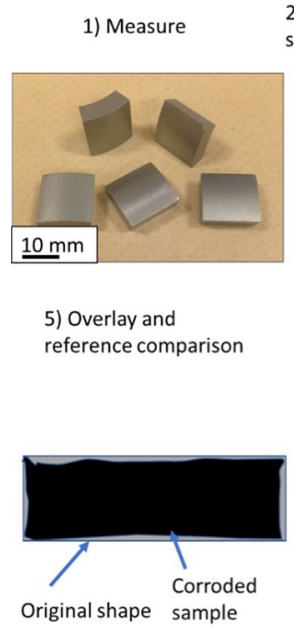

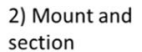

section
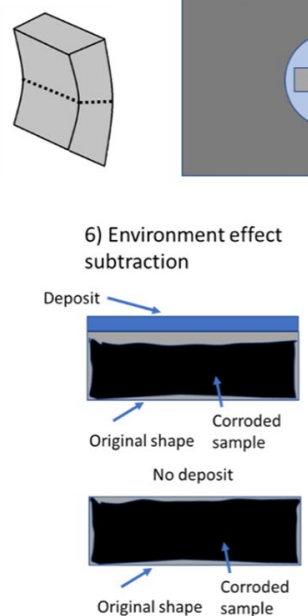

3) Take images

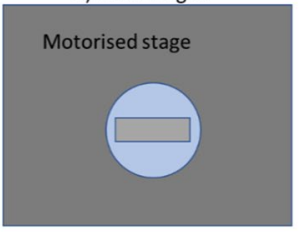

7) Plot
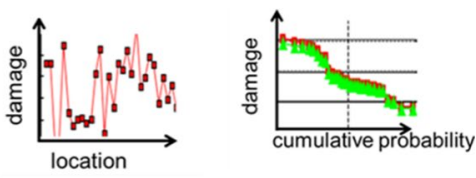

Fig. 3 Schematic diagram of the dimensional metrology process (Color figure online)

distribution of elements within the scales (resulting from both scale growth processes and scale/deposit/gas interactions) using elemental composition profiles.

\section{Results and Discussion}

\section{Dimensional Metrology}

The distribution of fireside corrosion-induced damage for the both alloys was collected every $200 \mathrm{~h}$. The cumulative distributions curves from these samples indicate the probability of finding an amount of damage greater than that value. For example, Fig. 4 gives data relating to Sanicro 25. Looking at the metal change curve at $650{ }^{\circ} \mathrm{C}$ (Fig. 4a), the point on the right-hand side (corresponding to the lower recorded damage) has an high cumulative probability (98\%), meaning that $98 \%$ of the surface will experience damage greater than that value and on the left-hand side a low cumulative probability (2\%). Additionally, the spread in metal change between the points of highest probability and the lowest probability gives an idea of the homogeneity of the corrosion experienced by the sample, where a smaller spread indicates more consistent corrosion. As such, the slope is generally associated with the homogeneity of the corrosion process across a sample's surface.

For the samples exposed up to $1000 \mathrm{~h}$, the curves presented in the graphs given in Figs. 4 and 5 give the cumulative distributions of 3 samples. 
$* 200 \mathrm{~h} \boxminus 400 \mathrm{~h} \oplus 600 \mathrm{~h} \bullet 800 \mathrm{~h} \otimes 1000 \mathrm{~h}$
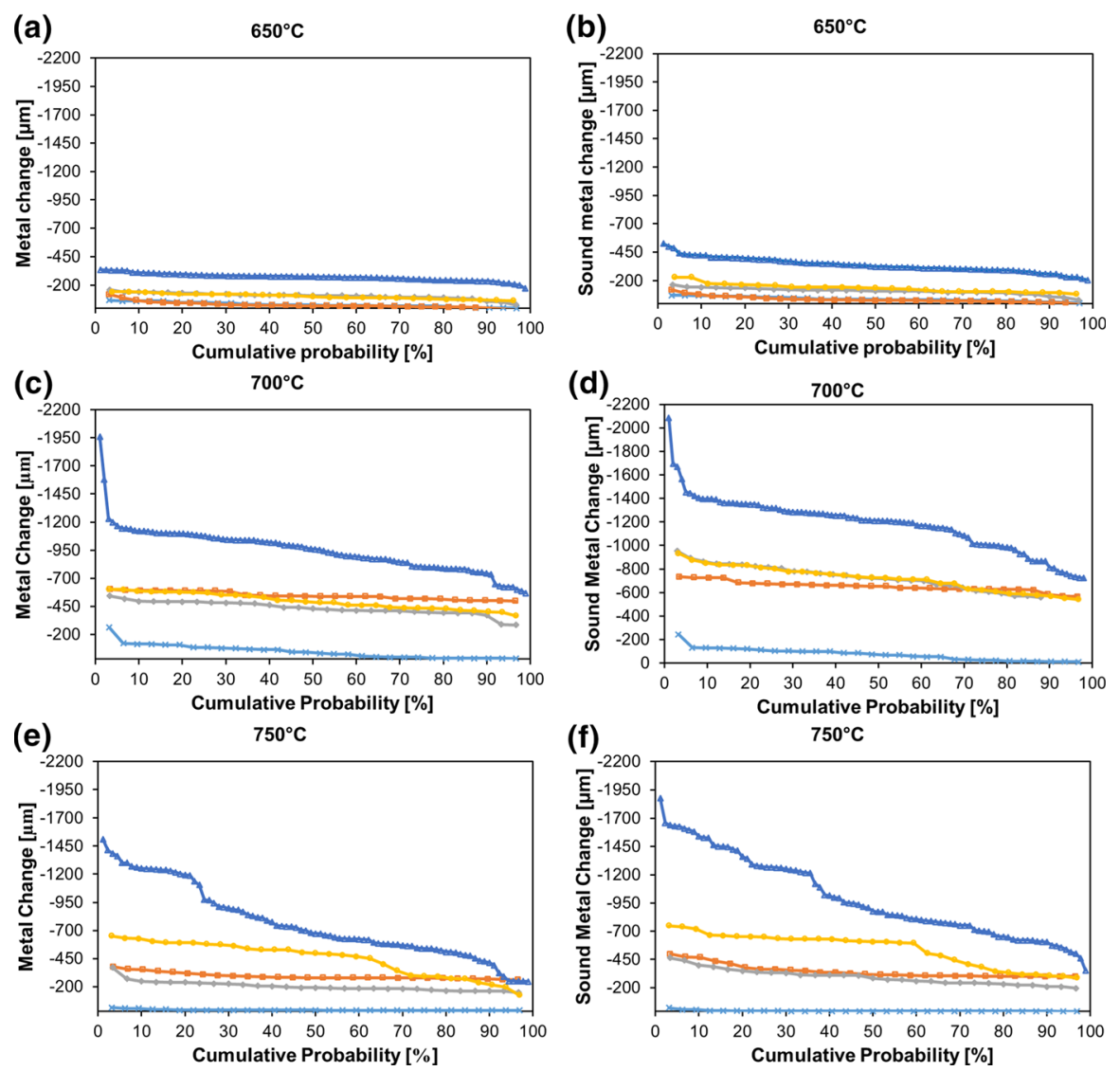

Fig. 4 Fireside corrosion-induced metal change and sound metal change for Sanicro 25 at the three different temperatures and exposure times; a, c, e show metal change for $650{ }^{\circ} \mathrm{C}, 700{ }^{\circ} \mathrm{C}$ and $750{ }^{\circ} \mathrm{C}$, respectively, while b, d, f sound metal change for $650{ }^{\circ} \mathrm{C}, 700{ }^{\circ} \mathrm{C}$ and $750{ }^{\circ} \mathrm{C}$, respectively (Color figure online)

\section{Sanicro 25 at $650^{\circ} \mathrm{C}$}

For Sanicro 25 at $650{ }^{\circ} \mathrm{C}$ (Fig. 4a, b), it can be seen that, until $600 \mathrm{~h}$ exposure, relatively low damage is present on the samples. The median metal change for $200 \mathrm{~h}$ and $400 \mathrm{~h}$ exposures is, respectively, $-26 \mu \mathrm{m}$ and $-20 \mu \mathrm{m}$, while the median sound metal changes are $-37 \mu \mathrm{m}$ and $-27 \mu \mathrm{m}$. These values suggest little metal loss or internal damage on the deposit coated sides of the samples. Between 600 and $800 \mathrm{~h}$, there is a significant increase in the fireside corrosion damage, with a metal change of $-109 \mu \mathrm{m}$ and $-102 \mu \mathrm{m}$, respectively. The median metal change at $800 \mathrm{~h}$ is 4 times higher than the damage observed at $200 \mathrm{~h}$ and at $400 \mathrm{~h}$. The sound metal change (Fig. 4b) shows a median value of $-110 \mu \mathrm{m}$ by $600 \mathrm{~h}$ and $-137 \mu \mathrm{m}$ by $800 \mathrm{~h}$ (Fig. 4a, b). The amount of median damage observed after $1000 \mathrm{~h}$ exposure is $-275 \mu \mathrm{m}$ for metal change and $-325 \mu \mathrm{m}$ for sound metal change. The curves in 
$* 200 \mathrm{~h} \boxminus 400 \mathrm{~h} \bullet 600 \mathrm{~h} \bullet 800 \mathrm{~h} \triangle 1000 \mathrm{~h}$

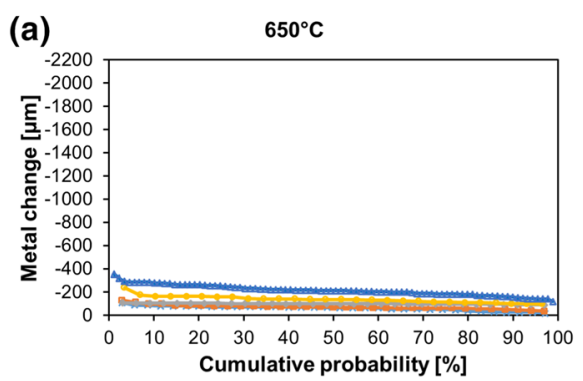

(b)
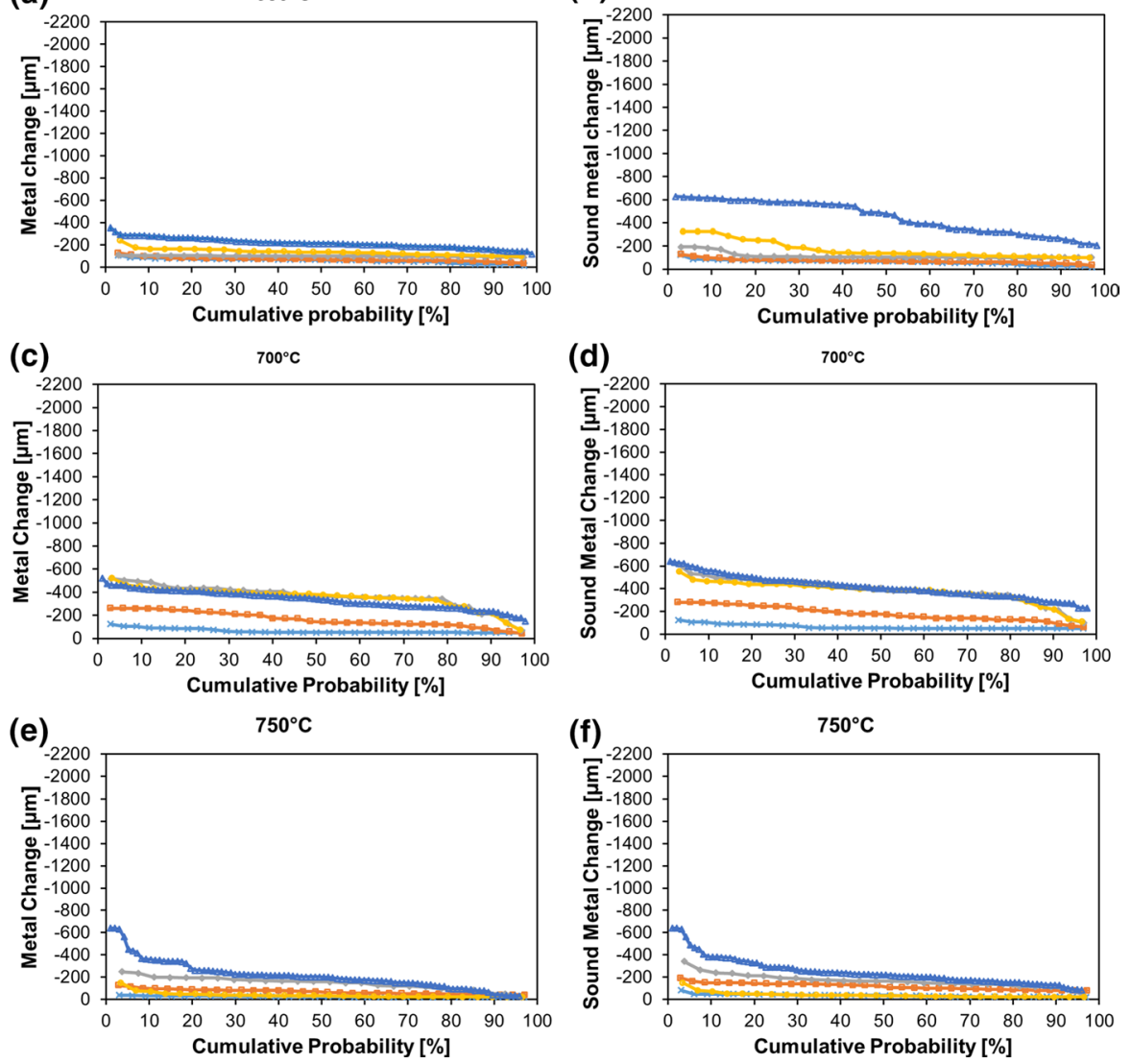

Fig. 5 Fireside corrosion-induced metal change and sound metal change for IN740 at the three different temperatures and exposure times: a, c, e show metal change for $650{ }^{\circ} \mathrm{C}, 700{ }^{\circ} \mathrm{C}$ and $750{ }^{\circ} \mathrm{C}$, respectively, while b, d, f sound metal change for $650{ }^{\circ} \mathrm{C}, 700{ }^{\circ} \mathrm{C}$ and $750{ }^{\circ} \mathrm{C}$, respectively (Color figure online)

Fig. 4a, b suggest that, at this temperature, the alloy is not into the incubation stage anymore, but with a low level of internal damage recorded, as indicated by the small or almost negligible difference between metal change and sound metal change values, which could indicate that the attack is not fully developed yet.

\section{Sanicro 25 at $700{ }^{\circ} \mathrm{C}$}

In Fig. 4c, d, the metal change and sound metal change, respectively, are shown for $700{ }^{\circ} \mathrm{C}$. In the figures, it can be seen that the damage propagation for Sanicro 25 starts sooner (at $200 \mathrm{~h}$ and $400 \mathrm{~h}$ ) than for the comparable samples exposed at $650{ }^{\circ} \mathrm{C}$, where the increase in the damage was seen at $400 \mathrm{~h}-600 \mathrm{~h}$. Sample exposed for $200 \mathrm{~h}$ shows a median metal change of $-34 \mu \mathrm{m}$, while the samples exposed for $400 \mathrm{~h}$ showed a median metal change of $-540 \mu \mathrm{m}$. Looking at the sound metal 
change, a similar behaviour is observed, with a median value of $-68 \mu \mathrm{m}$ recorded at $200 \mathrm{~h}$ and $-654 \mu \mathrm{m}$ at $400 \mathrm{~h}$. Similarly for $600 \mathrm{~h}$ and $800 \mathrm{~h}$, median metal change of $-430 \mu \mathrm{m}$ and $-485 \mu \mathrm{m}$ can be observed and median sound metal change of $-725 \mu \mathrm{m}$ and $-726 \mu \mathrm{m}$. Looking at the samples after $1000 \mathrm{~h}$, a median metal change of $-959 \mu \mathrm{m}$ was observed and a sound metal change of median $-1212 \mu \mathrm{m}$; an increase in absolute terms of 17 times compared to the sample exposed for $200 \mathrm{~h}$. Compared to the amount of damage seen at $650{ }^{\circ} \mathrm{C}$ (Fig. $4 \mathrm{a}, \mathrm{b}$ ), the alloys showed an increase in both metal change and sound metal change, suggesting that the alloy moved into the propagation stage. This includes the development of internal attack/ damage, which continues to increase in extent with exposure time.

\section{Sanicro 25 at $750{ }^{\circ} \mathrm{C}$}

In Fig. 4e, f, the distribution of metal and sound metal change at $750{ }^{\circ} \mathrm{C}$ is reported. From the figures, it can be observed that the amount of damage after the first $200 \mathrm{~h}$ exposure is low but increases after $400 \mathrm{~h}$ of exposure with median metal change of $-279 \mu \mathrm{m}$ (which represent about half the amount of damage shown at $700{ }^{\circ} \mathrm{C}$, but is higher than the one at $650{ }^{\circ} \mathrm{C}$ ). At $600 \mathrm{~h}$, the Sanicro 25 shows a similar median metal change $(-190 \mu \mathrm{m})$ to that found at $400 \mathrm{~h}$, but the spread of the values is higher than the one at $400 \mathrm{~h}$, meaning a less homogenous distribution of the damage. A further increase in the amount of metal lost has been observed at $800 \mathrm{~h}$. After $1000 \mathrm{~h}$ exposure, the distribution of the damage is less uniform around the surface of the metal, as can be seen in the cumulative probability plot, which shows a higher slope. The median value of the metal change increases to $-673 \mu \mathrm{m}$. Similar observations can be made for sound metal change. The slope of the curves shown in Fig. 4f increases with the time; the increase is more evident after $800 \mathrm{~h}$ and $1000 \mathrm{~h}$ exposure. This is related with a less homogenous distribution of both, the surface recession and the internal damage, around the samples. Comparing this with the data for the 650 and $700{ }^{\circ} \mathrm{C}$ samples (for the same alloy; Fig. 4), the amount of median change (both metal and sound metal) appears to be lower that at $700{ }^{\circ} \mathrm{C}$, and higher at $650{ }^{\circ} \mathrm{C}$, before dropping again at $750{ }^{\circ} \mathrm{C}$. This behaviour is consistent with moving across the corrosion peak.

\section{IN740 at $650^{\circ} \mathrm{C}$}

The effects of the same exposure conditions were studied for the alloy IN740.

In Fig. 5a, b, the data for metal and sound metal change at $650{ }^{\circ} \mathrm{C}$ are shown. At an early stage of exposure $(200 \mathrm{~h})$, the alloy seems to suffer low damage (median metal change $-67 \mu \mathrm{m}$ ), but still greater than Sanicro 25 (median-26 $\mu \mathrm{m}$ ). Similar behaviour has been found after $400 \mathrm{~h}$, with a median metal change of $-72 \mu \mathrm{m}$ and small portion of the metal showing a higher damage. At these times of exposure, little presence of internal damage was observed. The amount of surface damage undergoes a small increase for both $600 \mathrm{~h}$ and $800 \mathrm{~h}$ exposure, with a median metal change of $-101 \mu \mathrm{m}$ and $-137 \mu \mathrm{m}$, respectively. For these exposure times as well, the amount of internal damage was small and only small portions of the samples experienced it, with a maximum value of the sound metal change 
of $-125 \mu \mathrm{m},-129 \mu \mathrm{m},-194 \mu \mathrm{m}$ and $-326 \mu \mathrm{m}$, respectively, for $200 \mathrm{~h}, 400 \mathrm{~h}, 600 \mathrm{~h}$ and $800 \mathrm{~h}$. An increase in damage was observed at $1000 \mathrm{~h}$, where the median value of the metal change reached $-214 \mu \mathrm{m}$. The distribution of this damage seems to be relatively uniform around the sample; a small probability (below 10\%) of finding damage above $300 \mu \mathrm{m}$ could be related to pitting. An increase in the sound metal change was observed as well (median sound metal change $-474 \mu \mathrm{m}$ ), but in this case the distribution plot shows a more uniform behaviour (shown by the lower slope of the curve). The difference between the metal change and sound metal change is due to the development of internal corrosion attack at this temperature $\left(650{ }^{\circ} \mathrm{C}\right)$.

\section{IN740 at $700{ }^{\circ} \mathrm{C}$}

Cumulative probability distributions of corrosion damage for the different times at $700{ }^{\circ} \mathrm{C}$ exposure are shown in Fig. $5 \mathrm{c}$, d. These distributions of metal damage are mostly even after all exposure times, with the exception of samples after $600 \mathrm{~h}$ and $800 \mathrm{~h}$, where small fractions of the sample surfaces show lower damage with respect to the rest of the sample.

After $200 \mathrm{~h}$ exposure, the alloy shows a median metal change of $-52 \mu \mathrm{m}$ (and no internal damage), while after $400 \mathrm{~h}$ the material starts to show higher levels of damage, both from the surface and internally (median metal change- $142 \mu \mathrm{m}$, median sound metal change $-173 \mu \mathrm{m})$. At $800 \mathrm{~h}$ and $1000 \mathrm{~h}$, the alloy shows similar median metal changes of $-376 \mu \mathrm{m}$ and $-338 \mu \mathrm{m}$, respectively. The amount of sound metal change show median values of $-389 \mu \mathrm{m}$ for $800 \mathrm{~h}$ and $-400 \mu \mathrm{m}$ for $1000 \mathrm{~h}$. Comparing the median damage observed at $700{ }^{\circ} \mathrm{C}$ (Fig. 5c, d) with the median damage recorded at $650{ }^{\circ} \mathrm{C}$ (Fig. 5a, b), an increase in median metal change can be highlighted, before dropping again at $750{ }^{\circ} \mathrm{C}$. This correlates with the typical bell-shaped curve for the corrosion damage, which depends on the chemistry of the environment as well as the alloy chemistry.

\section{IN740 at $750^{\circ} \mathrm{C}$}

Lower damage (both metal and sound metal change) was recorded at $750{ }^{\circ} \mathrm{C}$ than at $700{ }^{\circ} \mathrm{C}$, as can be seen in Fig. 5e, f, for metal change and sound metal change, respectively. The amount of damage after $200 \mathrm{~h}$ exposure was below $-100 \mu \mathrm{m}$ (median metal change $-24 \mu \mathrm{m}$ ) which is lower than the median damage recorded at both $650{ }^{\circ} \mathrm{C}$ and $700{ }^{\circ} \mathrm{C}$. The distribution of the damage on the surface is mostly homogeneous at this exposure time. After $400 \mathrm{~h}$ exposure, there is an increase in the damage, with a median metal change of $-62 \mu \mathrm{m}$. The sound metal change distribution starts to increase compared to the metal change, with median values of $-35 \mu \mathrm{m}$ and $-108 \mu \mathrm{m}$ for $200 \mathrm{~h}$ and $400 \mathrm{~h}$ exposure, respectively. After $600 \mathrm{~h}$ exposure, a bigger increase in the damage was measured, with the damage increasing by about 6.5 times compared to the sample exposed for $200 \mathrm{~h}$ (median metal change $-157 \mu \mathrm{m})$. At this exposure time, small areas with higher levels of damage started to appear, as can be seen from the metal change distribution in Fig. 5e.

After the full $1000 \mathrm{~h}$ exposure, the metal change distribution has a median of $-200 \mu \mathrm{m}$. This is similar to the $-214 \mu \mathrm{m}$ median metal change found after $1000 \mathrm{~h}$ 
exposure at $650{ }^{\circ} \mathrm{C}$. However, the median sound metal change, after $1000 \mathrm{~h}$ at $750{ }^{\circ} \mathrm{C}(-218 \mu \mathrm{m})$, is significantly lower than the median sound metal change at $650{ }^{\circ} \mathrm{C}(-474 \mu \mathrm{m})$. From $650{ }^{\circ} \mathrm{C}$, the median metal change increases to a higher value at $700{ }^{\circ} \mathrm{C}$. However, comparing these values to those at $750{ }^{\circ} \mathrm{C}$, it shows a decrease in median metal change values with further increases in temperature. By contrast, for the median sound metal change, a constant decrease with the temperature has been recorded between $650{ }^{\circ} \mathrm{C}$ and $750{ }^{\circ} \mathrm{C}$. This could mean that, at $750{ }^{\circ} \mathrm{C}$, the deposit destabilises, so that the corrosion damage would be restricted to incubation stage, and not able to develop fully.

\section{Median Damage Comparison}

In Fig. 6, the median, 95\%, and 5\% values for both metal change and sound metal change at the three different temperatures are reported for Sanicro 25 and IN740. The two materials show a peak in metal change around $700{ }^{\circ} \mathrm{C}$, highlighting that this is a critical metal temperature for both materials in these exposure conditions. At $750{ }^{\circ} \mathrm{C}$, both alloys show a decrease in damage relative to the values recorded at $700{ }^{\circ} \mathrm{C}$. Similarly, a drop in damage relative to $700{ }^{\circ} \mathrm{C}$ is recorded at $650{ }^{\circ} \mathrm{C}$. In the case of the IN740, the amount of damage recorded at $750{ }^{\circ} \mathrm{C}$ is even lower than that observed at $650{ }^{\circ} \mathrm{C}$ (for both metal change and sound metal change). This peak at $700{ }^{\circ} \mathrm{C}$ for both alloys illustrates the bell-shaped curve temperature dependence of fireside corrosion damage (originally found for austenitic stainless steels [16, 22-24]). The bell-shaped curves for the fireside corrosion damage is related to the deposit flux for the lower temperature, and the ratio between $\mathrm{SO}_{3}$ and $\mathrm{SO}_{2}$, which influences the stability of the deposit The temperature occurrence of these peaks is

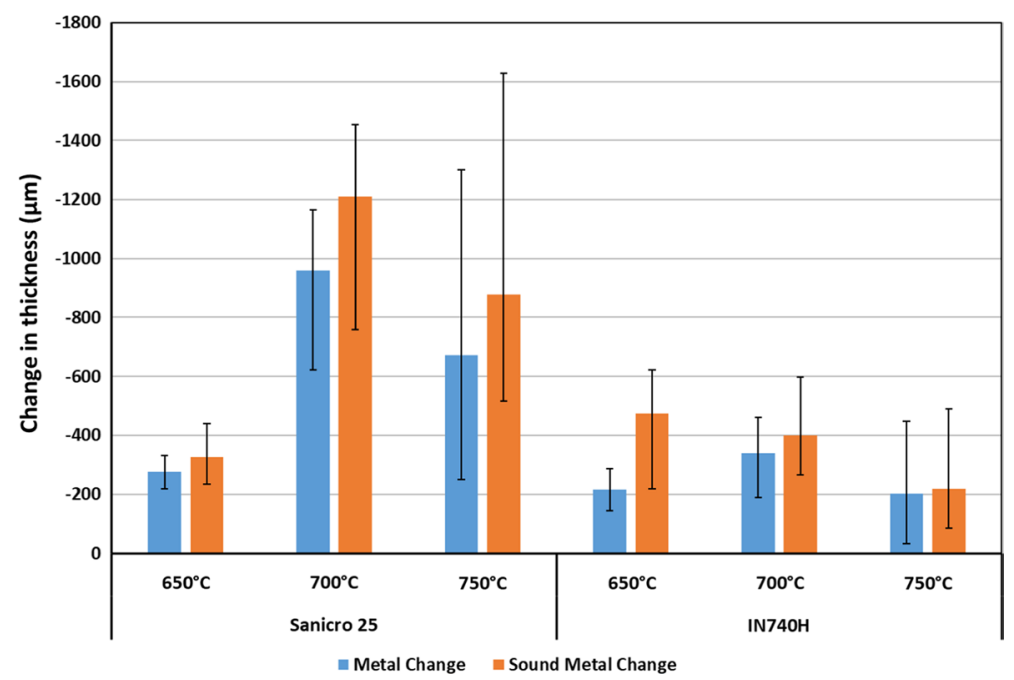

Fig. 6 Median, maximum and minimum metal changes for the two alloys, comparing different temperatures after $1000 \mathrm{~h}$ exposure under the simulated fireside corrosion conditions (range bars represent $95 \%$ and $5 \%$ probability) (Color figure online) 
strictly dependant on the combined effect of the chemistry of the gas environment, the chemistry of the deposit and the chemistry of the alloy substrate. For this reason, changing one of the three could result in a shift in temperature for the maximum corrosion damage observed. This is true for both metal change and sound metal change.

\section{SEM/EDS Cross-Sectional Analysis}

Samples for SEM/EDS were cross-sectioned and polished, but they were not etched to highlight the grain boundaries. In Fig. 7, SEM micrographs of the alloy Sanicro 25 are shown at the different exposure temperatures, after $1000 \mathrm{~h}$. It has been chosen to report only cross sections after $1000 \mathrm{~h}$ exposure, to highlight clearly what happens to these alloys when they are in their propagation stages (i.e. information about the propagation rate). The typical morphologies of the three samples are different from each other. At $650{ }^{\circ} \mathrm{C}$ (Fig. 7a), the sample shows a relatively thin scale/ deposit on it, which is in accordance with its low metal change data. On the other hand at $700{ }^{\circ} \mathrm{C}$ and $750{ }^{\circ} \mathrm{C}$ (Fig. $7 \mathrm{~b}$, c, respectively), thicker scale/deposit layers are present. For these latter two samples, the scale/deposit layers cannot entirely be shown on these micrographs, due to their thicknesses. The presence of these thicker
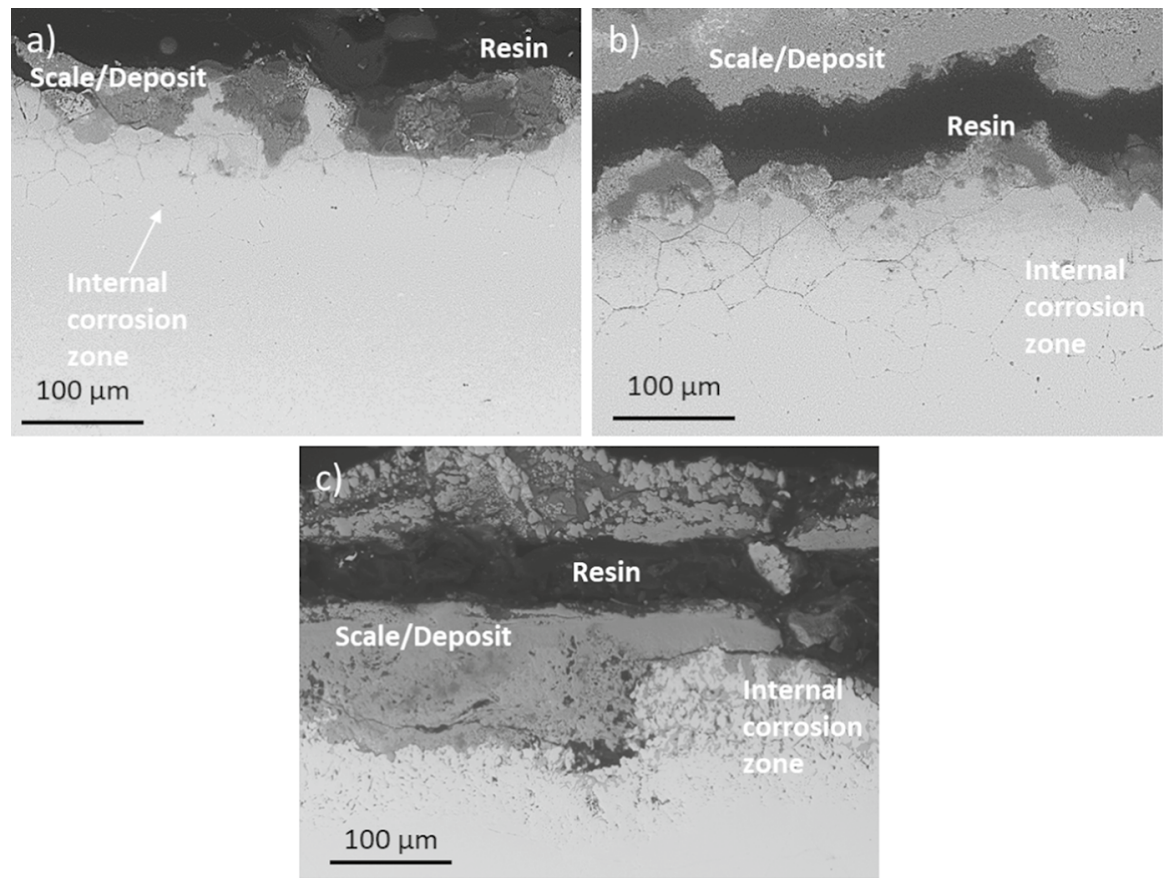

Fig. 7 SEM backscattered micrograph showing typical damage for Sanicro 25 at a $650{ }^{\circ} \mathrm{C}, \mathbf{b} 700{ }^{\circ} \mathrm{C}, \mathbf{c}$ $750{ }^{\circ} \mathrm{C}$ after $1000 \mathrm{~h}$ exposure. In the images, three regions can be clearly seen, scale/deposit, internal damage and alloy (brightest area). The black area is due to the resin used for the mounting 
scale/deposit layers was in agreement with the increase in the median metal change recorded at $700{ }^{\circ} \mathrm{C}$ and $750{ }^{\circ} \mathrm{C}$, compared to the sample exposed at $650{ }^{\circ} \mathrm{C}$.

Another feature that can be seen is the different extent and morphology of the internal damage at the three different exposure temperature. At $650{ }^{\circ} \mathrm{C}$ and $700{ }^{\circ} \mathrm{C}$ (Fig. 7a, b), the deepest damage is shown to be intergranular corrosion; however, this is not seen at $750{ }^{\circ} \mathrm{C}$. The sample at $700{ }^{\circ} \mathrm{C}$ also showed deeper internal damage than the sample exposed at $750{ }^{\circ} \mathrm{C}$.

The samples were analysed by EDS; the results of the analysis are shown in Fig. 8. For each sample, spectra were collected using area scans from three areas (i.e. scale/deposit, internal corrosion and underlying alloy). All the samples showed a variable range of compositions in the scale/deposit areas and internal corrosion zones. In the internal corrosion zones, there is a depletion of chromium, but the scales were enriched in chromium. This can be because the $\mathrm{Cr}$ diffuses into the scale from the internal corrosion zones; and the Cr-rich scale reacts with the deposit. The $\mathrm{Cr}$ depletion seems to be greater in percentage terms at $650{ }^{\circ} \mathrm{C}$ and $750{ }^{\circ} \mathrm{C}$, where, in the depleted area, it was found that there was $\sim 12 \mathrm{wt} \%$ decrease in $\mathrm{Cr}$. At $700{ }^{\circ} \mathrm{C}$ the depleted areas showed a decrease in $\sim 2 \mathrm{wt} \%$. Sub-surface $\mathrm{Cr}$ depletion in Sanicro 25 has previously been observed and identified as an indication of selective oxidation to form $\mathrm{Cr}_{2} \mathrm{O}_{3}$ [26]. Iron and nickel were also found in the scale; the iron could either come from the alloy, or from the deposit itself.

In Sanicro 25, nickel shows a different behaviour compared to $\mathrm{Cr}$. The amount of $\mathrm{Ni}$ increases (in percentage terms) on moving from the metal, to the internal corrosion zone and then into the scale/deposit. In all the samples, a diffusion of sulphur can be seen going from both the gaseous atmosphere and the scale/deposit, into the internal corrosion zones. The amount of $\mathrm{S}$ in the scale/deposit of the samples increases with temperature, going from $1 \mathrm{wt} \%$ at $650{ }^{\circ} \mathrm{C}$ to $7.8 \mathrm{wt} \%$ at $750{ }^{\circ} \mathrm{C}$ (Fig. 8). In the same way, the depth of the diffusion (i.e. internal corrosion zone) seems to be higher at $750{ }^{\circ} \mathrm{C}$. The composition of the samples return to the same values as the unexposed samples (see Fig. 8 and Table 1). The width of the internal corrosion zone shows a peak at $700{ }^{\circ} \mathrm{C}$, in accordance with the internal corrosion data that is included in the sound metal change data (compare Figs. 4, 7 and 8). In this sample, the extension of the internal corrosion zone is about $300 \mu \mathrm{m}$; three times higher than at the other two temperatures (Fig. 7). From Fig. 8 can also be seen the presence of $\mathrm{Cl}$ at $700{ }^{\circ} \mathrm{C}$, which could have contributed to the increase of the corrosion damage, this has been already reported in literature [36]. The presence of $\mathrm{Na}$ has been found as well, only at $650{ }^{\circ} \mathrm{C}$ and $750{ }^{\circ} \mathrm{C}$, while $\mathrm{K}$ has not been seen in any of the temperatures. That could be due to the spallation of the deposit or the deposit reacting with the gaseous environment.

In Fig. 9, EDS maps of the Sanicro 25 samples exposed at the three temperature are shown. It is worth noticing that the sample exposed at $700{ }^{\circ} \mathrm{C}$ required acquisition at lower magnitude, due to the thickness of the the scale/deposit region. In all cases, the scale/deposit region appears detached from the metal surface, but a difference in morphology in the three case can be seen. This might be responsible of the damage recorded for Sanicro 25 (see median metal and sound metal change in Fig. 6). Looking at the morphologies, it can be noticed that the scale/deposit region for the sample exposed at $700{ }^{\circ} \mathrm{C}$ appears more porous and less dense than that 
Fig. 8 EDS analyses for the Sanicro 25 at the three different temperatures; key elements only in scale/ deposit, internal corrosion zone and alloy (Fig. 7) (Color figure online)

observed at the other temperatures. This could be due to the interactions between the substrate, gas and deposit, which results in the most aggressive fluxing of protective scales at this temperature, and hence a less protective scale. This would have given rise to the higher metal and sound metal change observed at this temperature (see Fig. 6). Furthermore, the scale/deposit appears to be composed of a thick outer layer of an Fe-rich porous oxide layer, which is expected to give lower protection from corrosion than a Cr-rich oxide layer [37]. On the other hand, for both higher and lower temperatures $\left(650{ }^{\circ} \mathrm{C}\right.$ and $750{ }^{\circ} \mathrm{C}$, Fig. 9), a compact $\mathrm{Cr}$-rich oxide has been found, just above the Sanicro 25 surface. Cr-rich scale is usually responsible of enhanced corrosion protection. As the sulphate deposits first increase in reaction rate with temperature, and then destabilise, their ability to inhibit the formation of the protective Cr-rich scale will peak, here showing the most aggressive resonce at $700{ }^{\circ} \mathrm{C}$, as already reported [21], this destabilisation is due to the change in ratio between $\mathrm{SO}_{3} / \mathrm{SO}_{2}$. At lower temperature, the amount of $\mathrm{SO}_{3}$ is higher, leading to a more stable deposit on the surface. On the other hand at higher temperatures, the amount of $\mathrm{SO}_{2}$ can be found, which is responsible of the deposit destabilisation. The crossover between the two behaviours is around $700{ }^{\circ} \mathrm{C}$, which give rise to the bell-shaped curve peaked around $700{ }^{\circ} \mathrm{C}$ observed.The change in the deposit could explain the lower metal and sound metal changes observed for Sanicro 25 at both, $650{ }^{\circ} \mathrm{C}$ and $750{ }^{\circ} \mathrm{C}$ (see Fig. 6). It is important to notice the presence of $\mathrm{S}$ in the scale/deposit region in all of the Sanicro 25 samples. This could come from the deposit used (which was composed of sulphates) and/or the moreover $\mathrm{SO}_{2}$ present in the gaseous environment.

In Fig. 10a-c, typical images of IN740 samples exposed for $1000 \mathrm{~h}$ at $650{ }^{\circ} \mathrm{C}$, $700{ }^{\circ} \mathrm{C}$ and $750{ }^{\circ} \mathrm{C}$, respectively, are shown. From these images, different damage morphologies can be seen. The $650{ }^{\circ} \mathrm{C}$ image shows also presence of a large pit-like damage morphology, with further damage at the bottom of the peak spreading further into the metal (Fig. 10a).

The image in Fig. 10b shows the presence of internal damage areas, in particular, of grain boundary attack, even if a thick scale was not observed across the whole sample's exposed surface. The morphology of the metal surface looks irregular. This is reflected in the dimensional metrology, where the amount of metal change initially increased with the temperature. In the sample at $750{ }^{\circ} \mathrm{C}$ (Fig. 10c), the amount of internal damage shown is almost negligible. This feature was inline with the dimensional metrology data, where small amounts of internal damage were only observed in small areas.

As for Sanicro 25, the EDS data obtained from IN740 samples indicated a wide range of compositions in the scale/deposit and internal corrosion zones. Looking at the EDS data presented in Fig. 11, differences in compositions are shown. In all cases, the scale/deposit area is composed of mainly chromium and oxygen, which are also present in large quantities in the internal corrosion zone. On the other hand, diffusion towards the alloy of contaminant elements, such as S, has been also detected. The behaviour of the nickel alloy differs from the stainless steel one; an internal 

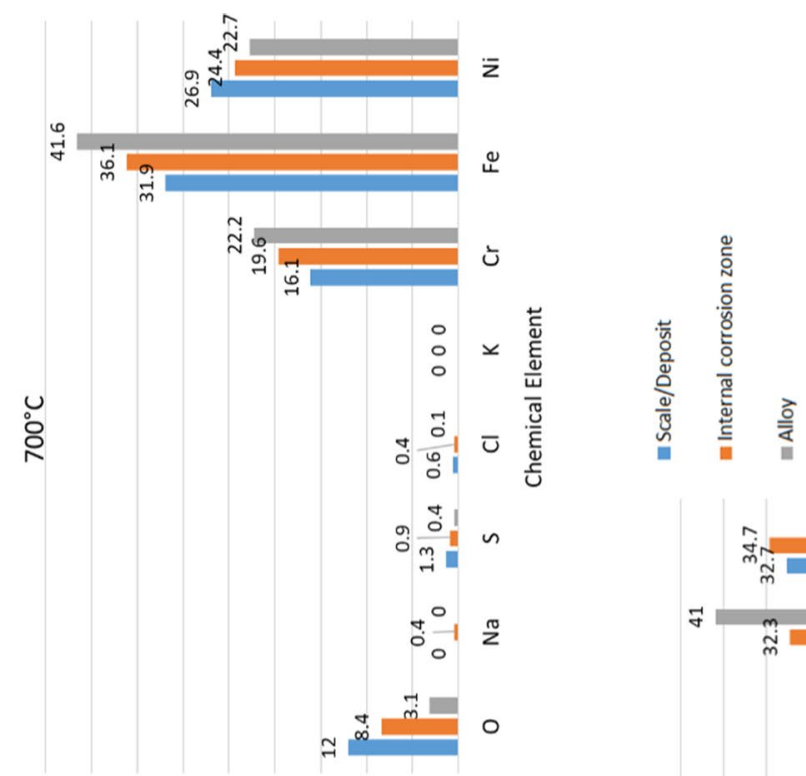

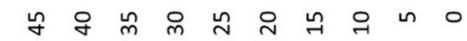

อ
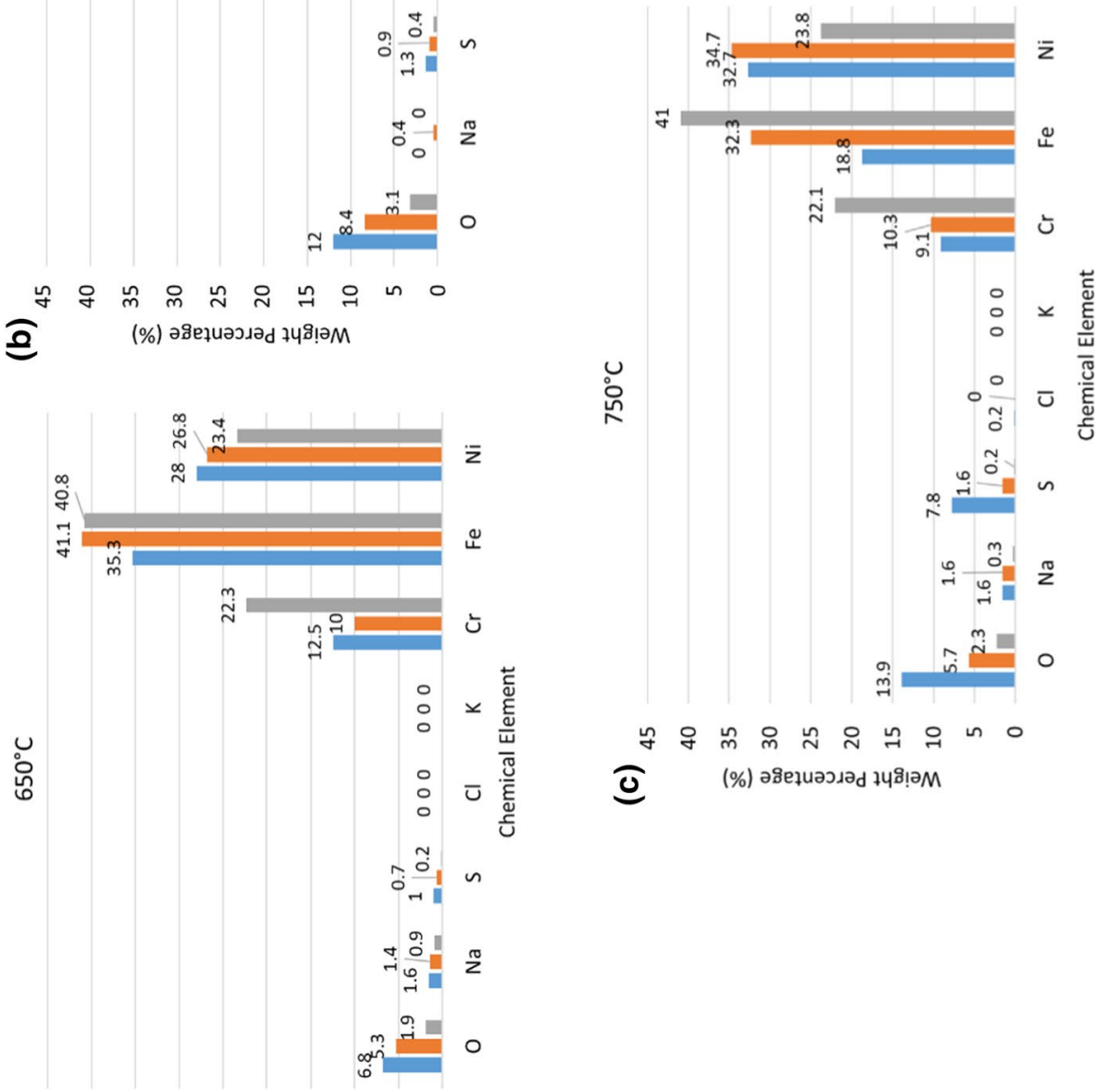

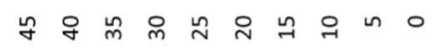

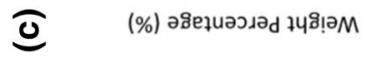

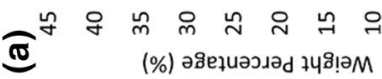



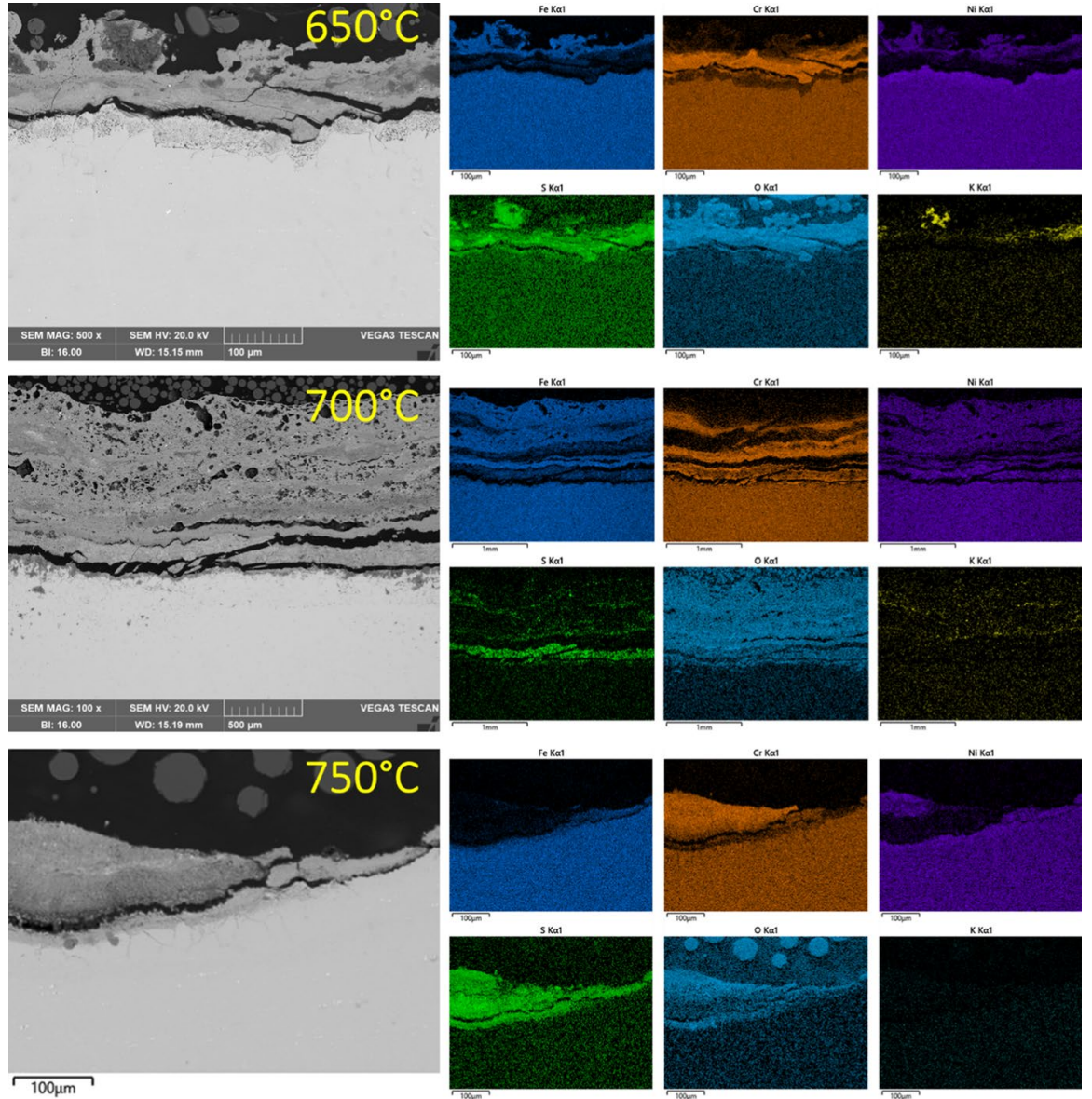

Fig. 9 SEM backscattered images and EDS maps analyses for the Sanicro 25 at three different exposure temperatures after $1000 \mathrm{~h}$. The image for the sample exposed at $700{ }^{\circ} \mathrm{C}$ has been taken at lower magnitude, to allow a complete scan of the scale/deposit region (Color figure online)

corrosion zone is not clearly visible in the sample exposed at $650{ }^{\circ} \mathrm{C}$ (Fig. 10a), but from the data shown in Fig. 11, a difference in concentration of nickel, chromium and cobalt has been observed. The area at the interface between scale/deposit and alloy seems to be enriched in $\mathrm{Cr}$, while is depleted in $\mathrm{Ni}$ and Co. Data in Fig. 11, linked to Fig. $10 \mathrm{~b}$, c, show that at $700{ }^{\circ} \mathrm{C}$ and $750{ }^{\circ} \mathrm{C}$ the alloy shows an internal corrosion zone. In such area, a change in composition has been observed. The scale/ deposit seems to be rich in chromium, and the content then decreases in the internal corrosion zone.

Different behaviour has been observed for the nickel and cobalt. The content of those element decreases from the alloy through the internal corrosion zone reaching a minimum in the scale/deposit area. The sample exposed at $700{ }^{\circ} \mathrm{C}$ showed a composition close to the undamaged one after about $200 \mu \mathrm{m}$ (compare Table 1 with 
Figs. 10 and 11). In contrast, the sample at $750{ }^{\circ} \mathrm{C}$ the concentration of $\mathrm{Cr}$ and $\mathrm{Co}$ observed was below the typical value of the alloy (compare Fig. 11 with Table 1), especially for cobalt, that was observed in $11 \%$ weight rather than $20 \%$. This could be due to a bigger extension of the damaged area, even if the pictures do not show clear evidences of corrosive attack below the internal corrosion zone. Looking at the contaminants' concentrations, a more extensive sulphur presence was found in the sample exposed at $700{ }^{\circ} \mathrm{C}$; this is reflected in the data collected by dimensional metrology, where the peak in metal change damage is shown at a temperature of $700{ }^{\circ} \mathrm{C}$ for IN740 (Fig. 6).

Figure 12 reports EDS maps from IN740. Particular attention has been paid to assessing the scale composition. It is worth to be noted that the composition of the area indicates that the scale is not formed only by the oxides, but it comprehends, also, elements form the deposits. As can be seen, going from $650{ }^{\circ} \mathrm{C}$ to $750{ }^{\circ} \mathrm{C}$, a progressively denser scale has been recorded, even if at $700{ }^{\circ} \mathrm{C}$ the scale appears to detach from the metal surface. A difference in composition can be observed as well, especially for the sample exposed at $700{ }^{\circ} \mathrm{C}$ (the sample that showed highest median metal change for IN740; see Fig. 6). This shows a significant part of the scale/deposit is formed by Fe-oxide, which is a more porous and less protective oxide than the Cr-rich oxides [38]. This scale formation could be due to the higher stability of the deposit at this temperature, leading to a more aggressive environment, causing a higher flux of more protective elements from the alloy to the surface, leaving the $\mathrm{Fe}$ as the remaining element to be oxidised. The greater presence of deposit elements $(\mathrm{K}, \mathrm{S})$ at $700{ }^{\circ} \mathrm{C}$ could be an indication of this deposit stability and have led to the higher median metal change for IN740 at $700{ }^{\circ} \mathrm{C}$ than at the other temperatures (see Fig. 6). At the other temperatures, as seen in Fig. 12, the presence of dense Ni-, Co-, Cr-rich oxide layers
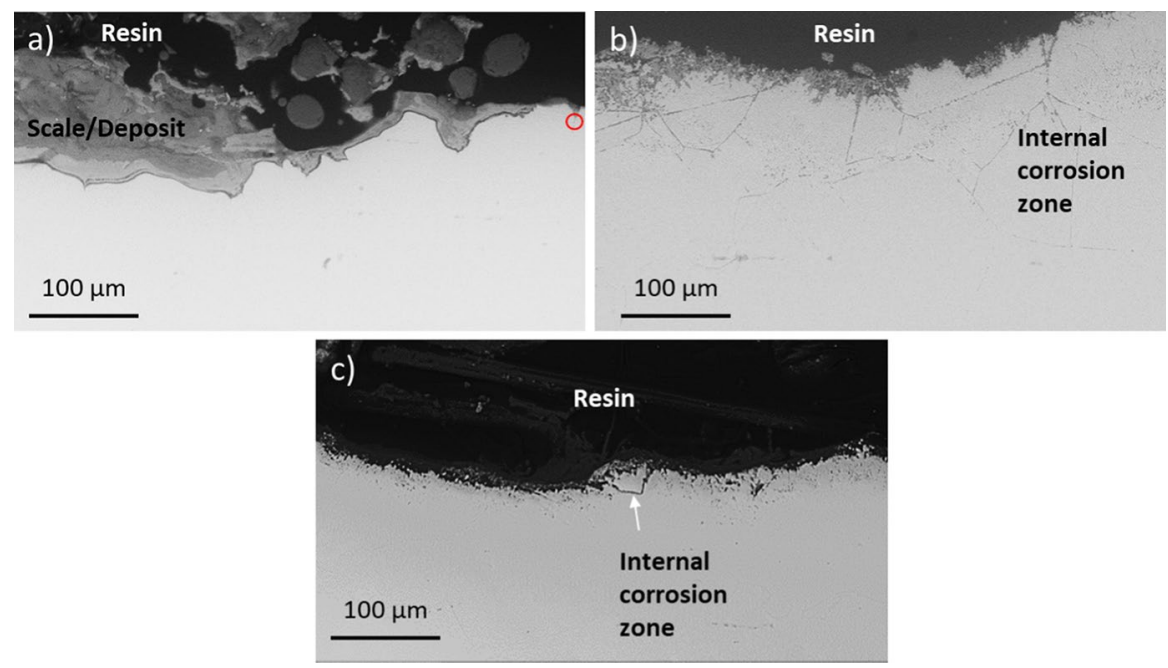

Fig. 10 SEM backscattered micrographs showing typical damage for IN740 at a $650{ }^{\circ} \mathrm{C}, \mathbf{b} 700{ }^{\circ} \mathrm{C}$ and $\mathbf{c}$ $750{ }^{\circ} \mathrm{C}$. In picture (a) the red circle shows the internal damage (Color figure online) 
(starting from top to bottom of the image) can be noted, which acted as a barrier between the environment and the samples. The presence of the $\mathrm{Cr}$-rich scale is due to the increased instability and a more reactivity of the deposit at $750{ }^{\circ} \mathrm{C}$, and a more stability and less reactivity at $650{ }^{\circ} \mathrm{C}$, leading to a lower corrosion damage in both cases. This could explain the decrease in the median metal change, as well as median sound metal change, observed for the IN740 samples exposed at $750{ }^{\circ} \mathrm{C}$, see Fig. 6 . The reason for this frequently reported bell-shaped peak in corrosion damage is related to the stability of the deposits generated under these exposure conditions. The deposit used for this work reacts with the gaseous environment to give an alkali iron tri-sulphate; this has a melting point of $\sim 550{ }^{\circ} \mathrm{C}$ [21], but becomes unstable above $\sim 680-700{ }^{\circ} \mathrm{C}$ due to the decrease in $\mathrm{SO}_{3}$ species in the gaseous environment with increasing temperature. Such changes in the deposit lead to a peak in corrosion damage between $650{ }^{\circ} \mathrm{C}$ and $700{ }^{\circ} \mathrm{C}$ (which has been reported by many authors, e.g. $[21,27]$ ). The peak damage depends on the alloy chemistry as well. It should be noted that this kind of behaviour has been observed previously in both nickel-based alloys (i.e. 263, 617 and 740) [27] and stainless steels (e.g., 347HFG and HR3C) [21]. Hussain et al. [21] showed in the paper that the peak in metal change was observed at lower temperature for similar conditions (gas composition $\mathrm{N}_{2} 73.8 \%, \mathrm{O}_{2} 4 \%, \mathrm{CO}_{2} 14 \%, \mathrm{H}_{2} \mathrm{O} 8 \%, \mathrm{SO}_{2}$ 1300 vppm, $\mathrm{HCl} 400$ vppm [21], compare to Table 2), but the paper investigated the behaviour of other steels (i.e. T92, 347HFG and HR3C), not Sanicro 25. On the other hand, it has been reported the ability of the IN740 to create an effective barrier to sulphur penetration, at temperature equal or above $700{ }^{\circ} \mathrm{C}$ [27]. In the current study, the two alloys exhibit similar trends, with peak of median metal change at $700{ }^{\circ} \mathrm{C}$, but with different level of damage; the median metal change in the Ni-based alloy being about three times lower at both $700{ }^{\circ} \mathrm{C}$ and $750{ }^{\circ} \mathrm{C}$ than the damage showed by Sanicro 25 (Fig. 6). From Fig. 11, it can also be seen that $\mathrm{Cl}$ has been found at $700{ }^{\circ} \mathrm{C}$, corresponding to the peak in metal change for both alloys (Fig. 6), suggesting that the gas would have had access to the metal surface. It has been observed by Jonsson [39] and Olivas-Ogaz [40] that $\mathrm{Cl}$ plays a crucial role in high-temperature corrosion, especially $\mathrm{HCl}$ coupled with $\mathrm{O}_{2}$. In this case, the $\mathrm{Cl}$ has the ability to form transition metal chlorides, which will decompose and leave a rough and porous, and hence unprotective, scale [40].

However, for median sound metal change, the two alloys show different behaviours; for Sanicro 25, the peak is still at $700{ }^{\circ} \mathrm{C}$, while for IN740 the maximum is at $650{ }^{\circ} \mathrm{C}$ and decreases with increasing temperature (Fig. 6). The amount of median sound metal change in IN740 is lower than in Sanicro 25 at temperature above $650{ }^{\circ} \mathrm{C}$ (three times lower at $700{ }^{\circ} \mathrm{C}$ and up to 4 times lower at $750{ }^{\circ} \mathrm{C}$ ), see Fig. 6.

Figure 13 shows the internal damage recorded for Sanicro 25 at the three different temperatures examined $\left(650{ }^{\circ} \mathrm{C}, 700{ }^{\circ} \mathrm{C}\right.$ and $\left.750{ }^{\circ} \mathrm{C}\right)$. It can be seen clearly that below the surface, there is a clear $\mathrm{Cr}$ depletion zone. Below the depletion zone, there is grain boundary attack, which is characterised by a different $\mathrm{Cr}$-content with respect to the grain itself. Starting from the sample exposed at $650{ }^{\circ} \mathrm{C}$, the absence of $\mathrm{Cr}$ at the grain boundaries can be noted. This is not followed, at this temperature, by the inward diffusion of $\mathrm{S}$ or $\mathrm{O}$ along the grain boundaries (within the resolution 

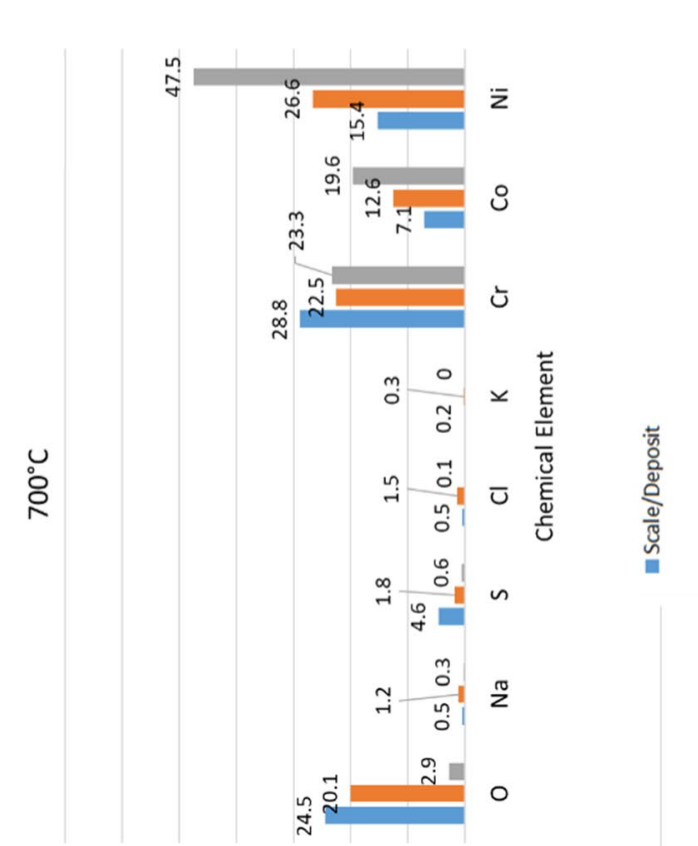

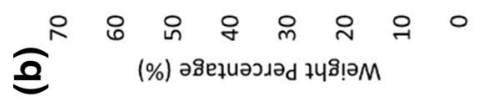
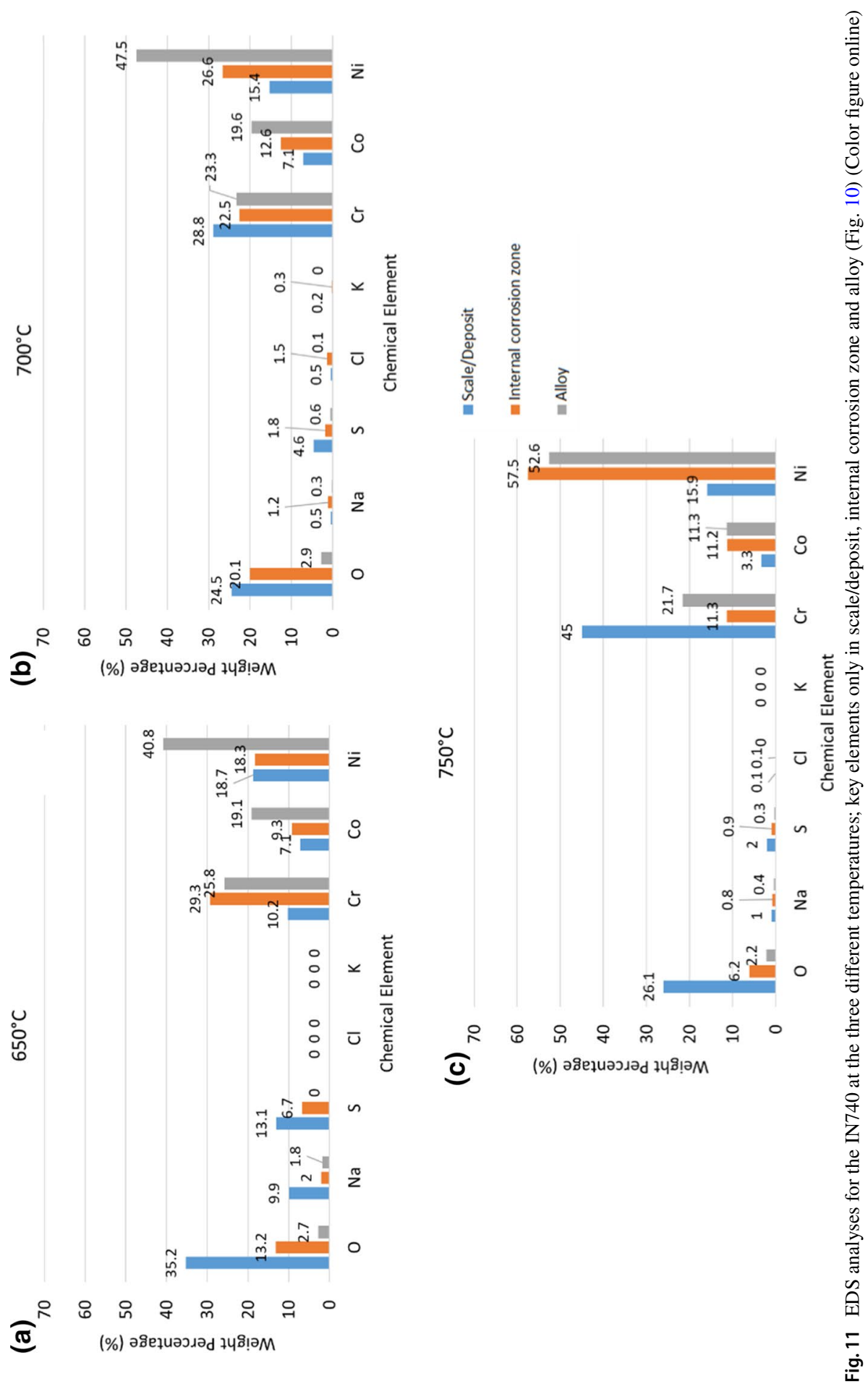

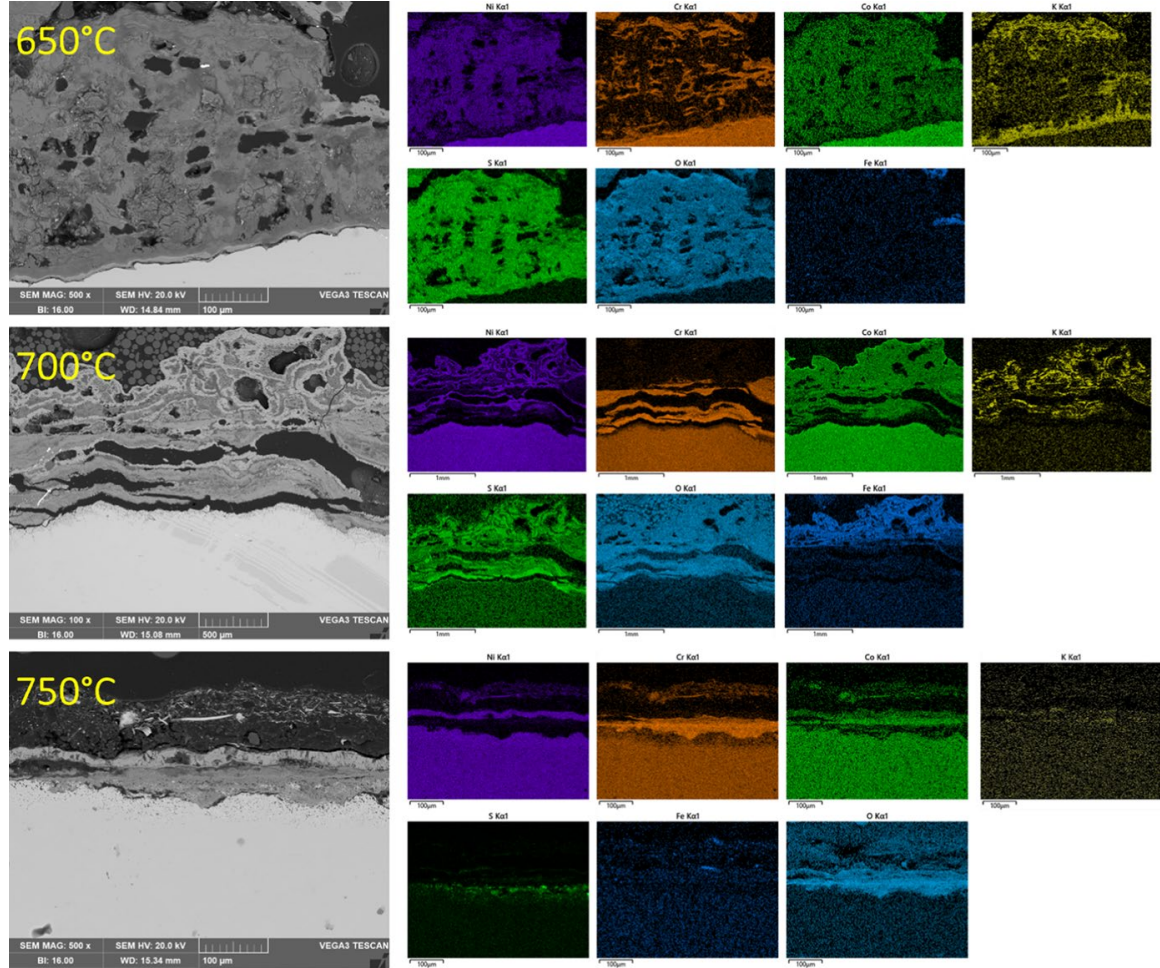

Fig. 12 SEM backscattered images and EDS maps analyses for the IN740 at three different exposure temperatures after $1000 \mathrm{~h}$. The image for the sample exposed at $700{ }^{\circ} \mathrm{C}$ has been taken at lower magnitude, to allow a complete scan of the scale/deposit region (Color figure online)

of the SEM used). The presence of Nb-rich precipitates in the alloy matrix can also be noted.

Figure 13 shows also Sanicro 25 exposed at $700{ }^{\circ} \mathrm{C}$ for 1000 h. The EDS maps are different with respect to Sanicro 25 exposed at $650{ }^{\circ} \mathrm{C}$. At grain boundaries, $\mathrm{Cr}$ presence has been found inside the depletion area at $700{ }^{\circ} \mathrm{C}$. This is followed by a inward diffusion of $\mathrm{S}$ and $\mathrm{O}$, which is similar to what has been already found for IN740 [27], where the $\mathrm{Cr}$ interacts with $\mathrm{S}$, forming $\mathrm{Cr} / \mathrm{S}$-rich areas, that, upon enclosing the grains, limit the ability of the $\mathrm{Cr}$ to diffuse from the bulk alloy (below the internal grain boundaries attack) to form a protective scale. This phenomenon is known as a "diffusion cell" and has been reported in literature for different materials exposed at high temperatures $[41,42]$. At $750{ }^{\circ} \mathrm{C}$, the grain boundaries show depletion of $\mathrm{Cr}$, with almost absent $\mathrm{S}$ and $\mathrm{O}$ inward diffusion. This could be explained by the deposit different stability at those temperature, which is dependant on the $\mathrm{SO}_{3}$ / $\mathrm{SO}_{2}$ ratio in the environment $[21,27]$. This gives rise to the bell-shaped curve for the metal change found in this work.

In Fig. 14, areas with internal damage for IN740 at $650{ }^{\circ} \mathrm{C}, 700{ }^{\circ} \mathrm{C}$ and $750{ }^{\circ} \mathrm{C}$ are shown. The grain boundary attack is not as evident as in the Sanicro 25 
samples, which is consistent with the dimensional metrology analysis (Fig. 6). The $\mathrm{Cr}$ depleted area is clearly visible only at $700{ }^{\circ} \mathrm{C}$ and $750{ }^{\circ} \mathrm{C}$. At $700{ }^{\circ} \mathrm{C}$, presence of $\mathrm{Al}$ and $\mathrm{O}$ is observed at grain boundaries. This could suggest the formation of $\mathrm{Al}$ oxide, which could potentially stop the diffusion of other species from the bulk alloy to the surface, preventing the formation of a protective Cr-rich oxide layer, as already observed [43]. It should be noted that the EDS data are in contradiction with the dimensional metrology data (Fig. 6), where the highest median sound metal change was found at $650{ }^{\circ} \mathrm{C}$. This could be due to the fact that the feature highlighted by SEM backscattered images, cannot be seen by optical microscopy images and not everything can be resolved with the resolution limit of the optical microscopy. Furthermore, in the SEM images, there cannot be a clear indication on where the original surface, so no indication of what the sound metal change would be in the presented surface point.

As can be seen by Figs. 13 and 14, the alloys used in this work seem to be susceptible to grain boundary corrosion under the exposure conditions used. The contrast changes around the grain boundaries in the micrographs indicates localised corrosion attack there. Since the grain boundaries were clearly visible (Figs. 7 and 10), there was no need to etch the alloys cross sections. To measure the grain boundaries size, several lines of known length were drawn on the BSE images of the alloys, and the number of grains intercepted by the lines counted, to derive an average grain size (known as Heyn method [44]; (in line with ASTM standard ASTM E112 - 13 [45]). Cross sectioning of samples will result in 2D representation of the $3 \mathrm{D}$ grain structure, as such it is very unlikely to hit the maximum grain dimension in a single cross section. Calculating the average with this methodology could result in an under-estimation of the actual grain size. This is exacerbated when grains are not equiaxed [39]. For these reasons, the averages were used as a tool for discussion, rather than accurate grain size measurements. Measurements from BSE image of the corroded area, although not homogeneous, show that attacked grains have an average size of about $41 \mu \mathrm{m}$, with a standard deviation of $6 \mu \mathrm{m}$ for Sanicro 25 and $46 \mu \mathrm{m}$ and a standard deviation of $9 \mu \mathrm{m}$, for IN740.

As already stated by Gollapudi [46] and Trindade [47], a homogenous and fine grain size distribution leads to the formation of an effective and uniform protective oxide for iron and nickel alloys with sufficient $\mathrm{Cr}$ levels, while a large grain distribution lead to a non-effective passive layer formation. Grain boundary corrosion of Sanicro 25 has been already reported in a sulphate-rich fireside corrosion environment [26]. It has also been reported that a nickel-based alloy, such as IN740, tends to form $\mathrm{Cr} / \mathrm{S}$-rich phases inside the internal corrosion zones restricting the amount of $\mathrm{Cr}$ available to form a protective oxide layer [27].

The dimensional metrology data (Figs. 4 and 5) showed that the evolution of the metal damage has three stages. The first one in which there are low levels of metal surface damage, and little attack on the grain boundaries; the second one in which the internal damage starts to grow along the grain boundaries and there is more surface damage; and, the third one in which there is more significant surface damage and the grain boundaries attack is fully developed. This behaviour can be linked to the ability of $\mathrm{Cr}$ to move in the bulk material. It has been seen, especially in the 

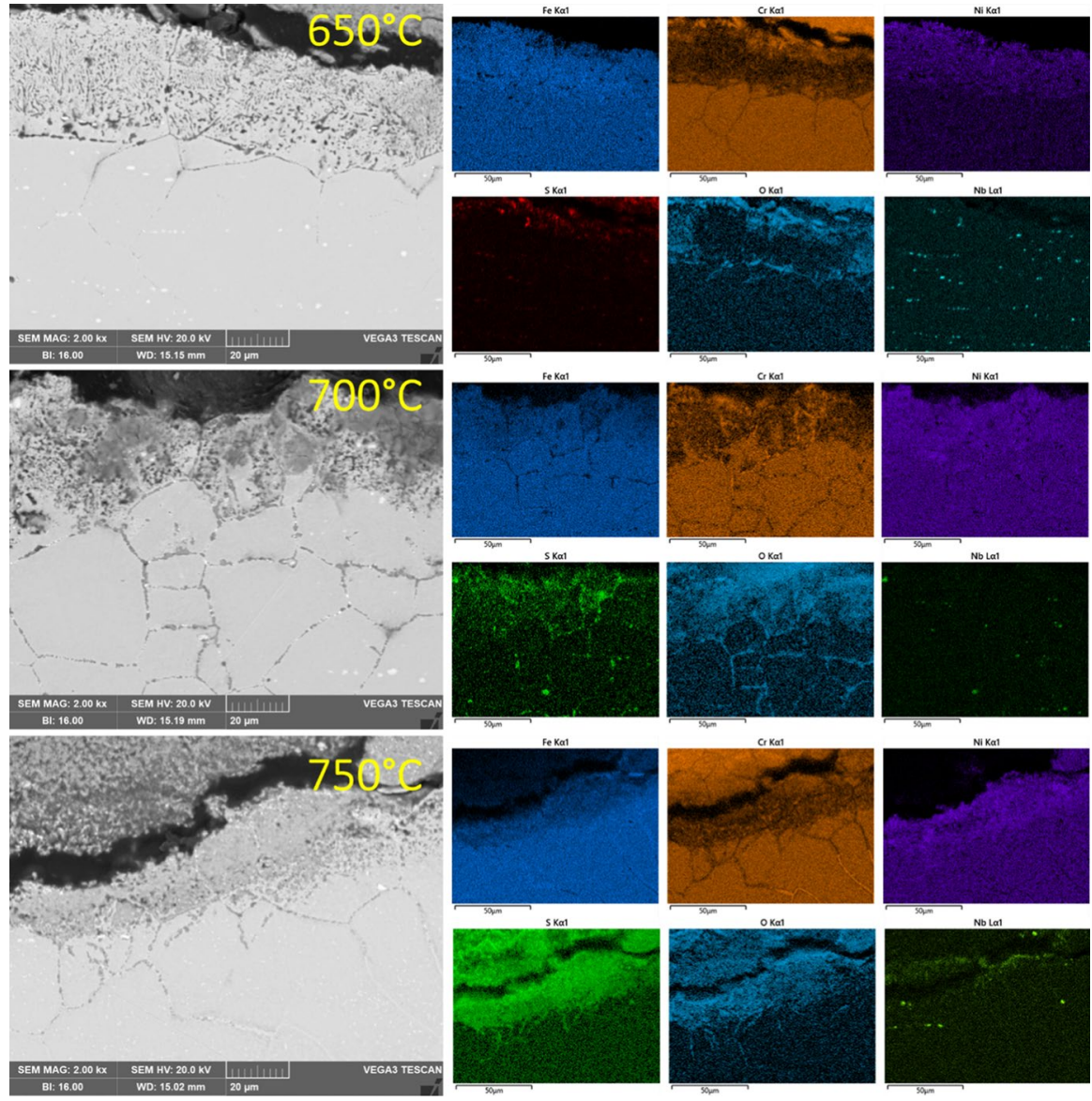

Fig. 13 SEM backscattered images and EDS maps analyses for the Sanicro 25 at three different exposure temperatures after $1000 \mathrm{~h}$. Images have been taken at higher magnitude with respect to Fig. 9 (Color figure online)

nickel-based alloy, that $\mathrm{Cr}$ has a tendency to bind with inwardly diffusing $\mathrm{S}$ initially on the grain boundaries [27], but later in the bulk of the grains. This can act as a barrier to $\mathrm{Cr}$ movement towards the surface, making the other elements interact with the environment forming less protective scales, which results in an increase in the metal damage.

An alternative explanation could be linked to the way in which $\mathrm{Cr}$ depletes within the internal corrosion zones in the samples and the balance between Cr-sulphide formation in the grain boundaries and alloy matrix. This could have led to the metal and sound metal changes seen in the data shown (Figs. 4 and 5). 

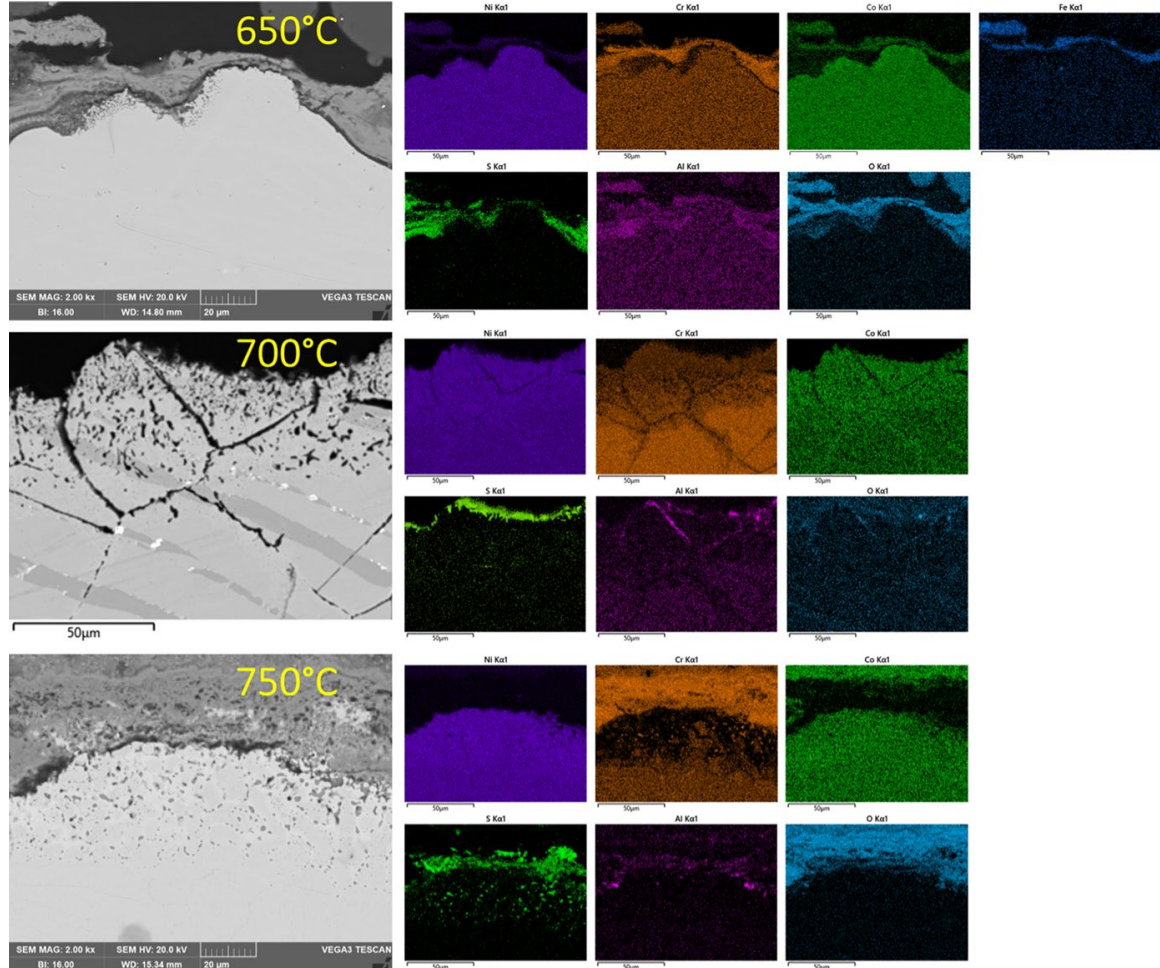

Fig. 14 SEM backscattered images and EDS maps analyses for the IN740 at three different exposure temperatures after $1000 \mathrm{~h}$. Images have been taken at higher magnitude with respect to Fig. 12 (Color figure online)

\section{Conclusions}

In this work, the fireside corrosion resistance of one stainless steel (Sanicro 25) and one Ni-based alloy (IN740) was tested at metal temperatures covering potential operational ranges for AUSC power plants, in a co-combustion scenario, for up to $1000 \mathrm{~h}$. Samples were exposed with deposit designed to produce accelerated alkali iron tri-sulphate-induced fireside corrosion. In this environment, IN740 showed a better corrosion resistance with respect to Sanicro 25 .

The two alloys studied showed the typical bell-shaped curve for corrosion damage temperature dependence. For Sanicro 25, the peak was identified at $700{ }^{\circ} \mathrm{C}$ for both metal change and sound metal change, with median metal change values of $-275 \mu \mathrm{m},-959 \mu \mathrm{m}$ and $-673 \mu \mathrm{m}$ at 650,700 and $750{ }^{\circ} \mathrm{C}$, respectively. IN740 showed a similar behaviour in terms of metal change, with a peak around $700{ }^{\circ} \mathrm{C}$, while the bell-shaped curve for sound metal change was not clearly identified. Median sound metal changes of $-474 \mu \mathrm{m},-400 \mu \mathrm{m}$ and $-218 \mu \mathrm{m}$ for IN740 were found at $650{ }^{\circ} \mathrm{C}, 700{ }^{\circ} \mathrm{C}$ and $750{ }^{\circ} \mathrm{C}$, respectively. This difference has been attributed to the differences in the stability of the resulting mixed deposits (of the applied salt, and any oxides/tri-sulphates formed from the base alloy), which could shift the 
temperature at which the peak appears. Nonetheless, at the lowest test temperature $\left(650{ }^{\circ} \mathrm{C}\right)$, both alloys showed a similar amount of median metal change. However, at $700{ }^{\circ} \mathrm{C}$ and $750{ }^{\circ} \mathrm{C}$, IN740 showed a lower metal change compared to Sanicro 25.

From the temporal development of the dimensional metrology data, it can be seen that there are three stages in the progression of the corrosion attack. In the first stage, there are low levels of metal surface damage, and little attack on the grain boundaries. In the second stage, the internal damage starts to grow along the grain boundaries and there is more surface damage. Finally, in the third stage, there is more significant surface damage (with median sound metal change approaching $-1000 \mu \mathrm{m}$ for Sanicro 25) and the grain boundary attack is fully developed (with median sound metal change exceeding $-1000 \mu \mathrm{m}$ for Sanicro 25), as would be expected for an alloy experiencing the propagation stage of fireside corrosion in accelerated corrosion tests. This has been linked to the formation of $\mathrm{Cr} / \mathrm{S}$-rich compounds in the internal corrosion zones (grain boundaries and matrix) that restricts the ability of $\mathrm{Cr}$ to move to the surface to maintain a protective oxide scale.

A different behaviour has been observed for IN740, where the dimensional metrology data showed a more even corrosion damage (metal change) on the samples' surfaces, i.e. a lower slope of the dimensional metrology distribution. This could be due to the ability of the IN740 to form a more protective oxide at those temperatures $\left(650{ }^{\circ} \mathrm{C}, 700{ }^{\circ} \mathrm{C}\right.$ and $\left.750{ }^{\circ} \mathrm{C}\right)$, due to the differences in $\mathrm{Cr}, \mathrm{Ni}$ and $\mathrm{Co}$ content, with respect to the Sanicro 25 .

$\mathrm{SEM} / \mathrm{EDS}$ analysis showed depletion of $\mathrm{Cr}$ in the areas with internal damage for both alloys. This behaviour was more evident in Sanicro 25, where the extent of the damaged areas was greater than for IN740. The corrosion damage observed with dimensional metrology has been explained as a result of $\mathrm{Cr}$ depletion, grain boundaries attack and deposit stability at the three different temperatures.

Acknowledgements This work was founded by EU Research Fund for Coal and Steel Project RFCS2015/709954 "Preparation for Commercial Demonstration Plant for $700{ }^{\circ} \mathrm{C}$ Operation", DP 700 - Phase 1.

Open Access This article is licensed under a Creative Commons Attribution 4.0 International License, which permits use, sharing, adaptation, distribution and reproduction in any medium or format, as long as you give appropriate credit to the original author(s) and the source, provide a link to the Creative Commons licence, and indicate if changes were made. The images or other third party material in this article are included in the article's Creative Commons licence, unless indicated otherwise in a credit line to the material. If material is not included in the article's Creative Commons licence and your intended use is not permitted by statutory regulation or exceeds the permitted use, you will need to obtain permission directly from the copyright holder. To view a copy of this licence, visit http://creativecommons.org/licen ses/by/4.0/.

\section{References}

1. Roadmap 2050:A Practical Guide to a Prosperous, Low-carbon Europe. Eur. Clim. Found. 2010.

2. State of play on the sustainability of solid and gaseous biomass used for electricity, heating and cooling in the EU. Eur. Comm. 2014. https://doi.org/10.1017/CBO9781107415324.004.

3. A policy framework for climate and energy in the period from 2020 to 2030. Eur. Comm. 2014. 
4. A. Froggatt and A. Hadfield, Deconstructing the European Energy Union: Governance and 2030 Goals. UK Energy Res. Cent. 2015.

5. G. Camarsa, J. Toland, and T. Hudson, et al, LIFE and Climate change mitigation. Eur. Union. 2015.

6. J. Watson, R. Gross, I. Ketsopoulou, and M. Winskel, Energy Policy 87, 685 (2015).

7. M. Sami, K. Annamalai, and M. Wooldridge, Progress in Energy and Combustion Science 27, 171 (2001).

8. A. H. M. Khodier, T. Hussain, N. J. Simms, J. E. Oakey, and P. J. Kilgallon, Fuel. 101, 53 (2012).

9. T. Hussain, A. H. M. Khodier, and N. J. Simms, Fuel 112, 572 (2013).

10. Y. Shao, J. Wang, F. Preto, J. Zhu, and C. Xu, Energies 5, 5171 (2012).

11. K. Nicol, Status of advanced ultra-supercritical pulverised coal technology. 2013.

12. L. Kloc, P. Dymáček, and V. Sklenička, Materials Science and Engineering A 722, 88 (2018).

13. M. Calmunger, G. Chai, S. Johansson, and J. Moverare, Transactions of the Indian Institute of Metals 69, 337 (2016).

14. G. Chai, M. Boström, M. Olaison, and U. Forsberg, Procedia Engineering 55, 232 (2013).

15. Y. Y. Dang, X. B. Zhao, Y. Yuan, et al., Materials at High Temperatures 33, 1 (2016).

16. C. P. O’Hagan, B. J. O’Brien, S. B. Leen, and R. F. D. Monaghan, Corrosion Science 109, 101 (2015).

17. R. Sandström, M. Farooq, Basic models for creep deformation in stainless steels. 2012;25-27.

18. Conference I, Interaction C. No Title. 2012.

19. B. Rutkowski, A. Gil, A. Agüero, et al., Oxidation of Metals 89, 609 (2018).

20. J. Stringer and I. G. Wright, Oxidation of Metals 44, 265 (1995).

21. T. Hussain, A. U. Syed, and N. J. Simms, Fuel 113, 787 (2013).

22. N. J. Simms, P. J. Kilgallon, and J. E. Oakey, Materials at High Temperatures 24, 333 (2007).

23. A. U. Syed, N. J. Simms, and J. E. Oakey, Fuel 101, 62 (2012).

24. N. J. Simms, J. Sumner, and T. Hussain, et al. Mater. Sci. Technol. (2012).

25. M. Montgomery and O. H. Larsen, Materials and Corrosion 53, 185 (2002).

26. B. Rutkowski, A. Gil, and A. Czyrska-Filemonowicz, Corrosion Science 102, 373 (2016).

27. G. Stein-brzozowska, D. M. Flórez, J. Maier, and G. Scheffknecht, Fuel 108, 521 (2013).

28. N. J. Simms, P. J. Kilgallon, and J. E. Oakey, Energy Materials 2, 154 (2008).

29. T. Hussain, N. J. Simms, J. R. Nicholls, and J. E. Oakey, Surface and Coatings Technology 268, 165 (2015).

30. N. J. Simms and A. T. Fry, Technology, 1192-1201 (2012).

31. ISO 14802:2012 Corrosion of metals and alloys-Guidelines for applying statistics to analysis of corrosion data.

32. ISO 17224:2012 Corrosion of metals and alloys-Test method for high temperature corrosion testing of metallic materials by application of a deposit of salt, ash, or other substances.

33. ISO 26146:2012 Corrosion of metals and alloys-Method for metallographic examination of samples after exposure to high-temperature corrosive environments.

34. S. R. J. Saunders and H. J. Grabke DBM. Guidelines for methods of testing and research in high temperature corrosion, The Institute of Metals, London. 1995;85.

35. J. Lu, Z. Yang, Y. Li, et al., Journal of Materials Engineering and Performance 27, 2855 (2018).

36. X. Montero, A. Ishida, M. Rudolphi, et al., Corrosion Science 173, 108765 (2020). https://doi.org/ 10.1016/j.corsci.2020.108765.

37. A. Persdotter, J. Eklund, J. Liske, et al., Corrosion Science 177, 108961 (2020).

38. T. Jonsson, S. Karlsson, H. Hooshyar, et al., Oxidation of Metals 85, 509 (2016). https://doi.org/10. 1007/s11085-016-9610-7.

39. T. Jonsson, N. Folkeson, M. Halvarsson, et al., Oxidation of Metals 81, 575 (2014). https://doi.org/ 10.1007/s11085-013-9468-X.

40. M. A. Olivas-Ogaz, J. Eklund, J. E. Svensson, et al., Oxidation of Metals 87, 801 (2017). https://doi. org/10.1007/s11085-017-9763-z.

41. H. E. Evans and M. P. Taylor, Oxidation of Metals 55, 17 (2001). https://doi.org/10.1023/A:10103 69024142.

42. S. Cruchley, H. Evans, and M. P. Taylor, Materials at High Temperatures 33, 465 (2016).

43. J. Lu, Z. Yang, Y. Li, et al., Oxidation of Metals 89, 609 (2018). https://doi.org/10.1007/ s11085-017-9804-7.

44. G. Vander Voort, Grain Size Measurement, Practical Applications of Quantitative Metallography, eds. J. Steele and J. McCall (West Conshohocken, PA: ASTM International, 1984), pp. 85-131. https://doi.org/10.1520/STP30216S 
45. ASTM E112-13. Standard Test Methods for Determining Average Grain Size.

46. S. Gollapudi, Corrosion Science 62, 90 (2012).

47. V. Trindade, H. J. Christ, and U. Krupp, Oxidation of Metals 73, 551 (2010).

48. T. Hussain, N. J. Simms, and J. R. Nicholls, Materials and Corrosion 65, 197 (2014).

Publisher's Note Springer Nature remains neutral with regard to jurisdictional claims in published maps and institutional affiliations. 